\title{
نظام التربية الإسلامية في المملكة العربية السعودية
}

\author{
فهز بن مطر الثهراني \\ قسم الثربعة بمعهد العلوم الإسلامية والعربية بجاكرتا \\ Email: fahad_mathar@gmail.com
}

\begin{abstract}
Abstrak: Artikel ini menjelaskan kajian deskriptif tentang sistem pendidikan Islam di Arab Saudi. Sistem ini bersumber dari agama Islam, dan keunggulan dan kelengkapan dan universalitasnya agar semua subsistem itu sejalan dengannya. Sistem pendidikan Islam di Kerajaan Arab Saudi merupakan langkah pertama untuk menumbuhkan dan mengembangkan individu, keluarga, dan masyarakat. Sistem pendidikan Islam diformulasikan untuk memajukan pendidikan Islam sebagai misi untuk memenuhi tantangan yang dihadapi dunia Muslim kontemporer dan untuk memenuhi kebutuhan dan aspirasi masa depan; sekaligus untuk memperjelas konsep filsafat pendidikan, kurikulum, dan pendidikan, metode, dan tujuan, prinsip-prinsip, dan berbagai aspek praktis lainnya. Sistem pendidikan Islam di Arab Saudi mempunyai sejumlah karakteristik seperti berketuhanan, universal, rasional, berkesinambungan, seimbang dan realistis.
\end{abstract}

Kata Kunci: pendidikan Islam, Arab Saudi, sistem pendidikan

Abstract: This article contains a descriptive study about the education system in Saudi Arabia, which is based on Islamic teachings. This system maintains the universality and comprehensiveness of Islam education, which sets the foundation of all subsystems. Islamic education system in the Kingdom of Suadi Arabia (KSA) begins with developing and nurturing individuals, family and society. The system is designed to enhance Islamic education in order to prepare Muslim generations in facing future needs and challenges. It is therefore important to elucidate the philosophy, curriculum, and principles of Islamic education. Islamic education system in the Kingdom of Saudi Arabia has several characteristics, including divinity, unversal, rational, continuous, balance, and realistic.

Keywords: Islamic education, Saudi Arabia, education system

$$
\begin{aligned}
& \text { إن الحديث في نظام التربية الإسلامية ليس حديثا } \\
& \text { يسطر في ورق ويصفف في المجلدات، بل هو أساس } \\
& \text { عقدي شرعي تقوم عليه أنظمتنا التربوية لتستمر في } \\
& \text { التطوير والتحسين بناء على هذا الأساس المتين. قال } \\
& \text { تعالى:اليوم أكملت لكم دينكم وأتممت عليكم نعمتي } \\
& \text { ورضيت لكم الإسلام دينا'، ويقول النبي صلى الله عليه } \\
& \text { وسلم من حديث العرباض بن سارية: " ..تركتكم على ورصيّي }
\end{aligned}
$$

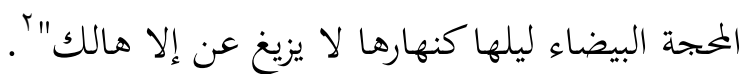

$$
\begin{aligned}
& \text { ا سورة المائدة، الآية: (ب). }
\end{aligned}
$$

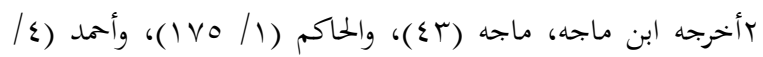

$$
\begin{aligned}
& \text { بr (1)، وصححه الألباني في سلسلة الأحاديث الصحيحة. }
\end{aligned}
$$

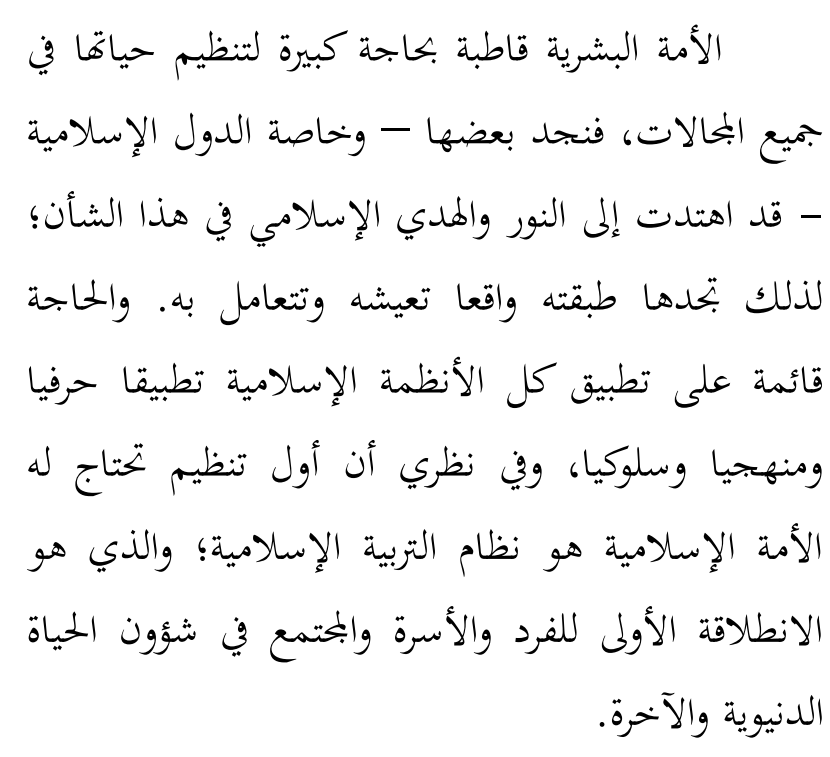


وإن شعورنا اليوم بالحاجة إلى نظام تربوي تساؤلات البحث

بهذا المنظور فإن الباحث سيجيب على سؤال، وهو

ما هو نظام وأسس التربية الإسلامية في المملكة؟

\section{أهداف البحث وأهميته}

يهدف البحث إلى توضيح نظام وأسس التربية الإسلامية في المملكة. وتتمثل أهميته في وصف وعرض لوض واقع التربية في المملكة في تطبيق نظام التربية الإسلامية الفريدة المعاصرة من بين تجارب الدول الإسلامية.

\section{منهج البحث}

تعد هذه الدراسة من البحوث الوصفية التي تمف إلى وصف الظاهرة المدروسة من حيث طبيعتها، ودرجة وجودها، وبعض الأبعاد المهمة حولها، وتفسيرها .

\section{الدراسات السابقة}

تعد الدراسات في هذا المحال من أوفر الدراسات على المستوى الإسلامي والعربي نظرا لملامستها للواقع وكثرة المتخصصين فيها.وقد تكون دراسة سليمان الحقيلهي المرجع لكثير من الدراسات من حيث النظام والأسس، ففيها عرض الأسس العامة التي يقوم عليها التعليم في المملكة كما نصت عليها سياسة التعليم.

\section{مفهوم التربية الإسلامية}

إن التربية الإسلامية تمثل المنهج الذي يحقق التطبيق

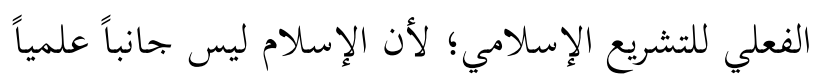

م صالح العساف، المدنحل إلى البحث في العلوم السلوكية، (الرياض:

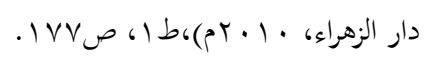
جسليمان بن عبد الرحمن الحقيل،نظام وسياسة التعليم في المملكة العربية
إسلامي.لذلك مازالت الحاجة قائمة لتحديد أمرين اثنين، هما تقديم التربية الإسلامية كرسالة لمواجهة التحديات التي تواجه العالم الإسلامي المعاصر وتلبية حاجاهوتطلعاته المستقبلية؛ وإبراز التفاصيل والتطبيقات التربوية المتخصصة لمذه التربية مثل: فلسفة التربية، والمناهج، وميادين التربية، وطرقها، وأهدافها وغير ذلك من الأصول والجوانب التطبيقية العملية، والتي تعيش في هذا الجانب عالة على وصنى النظم التربوية الأجنبية والمستوردات التي تحملها معها

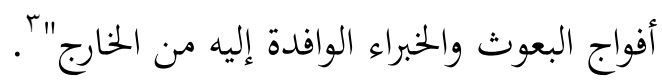
عرض النموذج المشرف من نظام المملكة التربوي الإسلامي، ووصف الواقع لمذا النظام التربوي بكل محتوياته العلمية والأخلاقية والسلوكية والمهارات المختلفة والحضارية وتطبيقاتا في كافة المستويات والتي أنتجت لنا

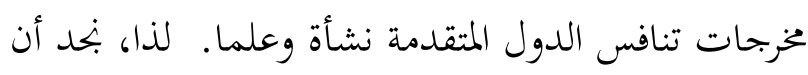
سياسة التعليم الموضوعة احتوت على مواد انبثقت من الإسلام الذي تدين به الأمة عقيدة وعبادة وخلقاً وشريعة

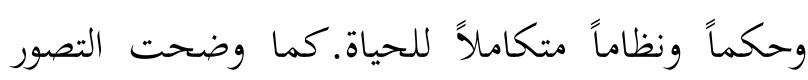

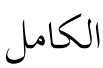

الإسلامي

للكون،والإنسان،والحياة،والأخلاق ،والعلم؟ .

rبدرية صالح الميمان،"أسس التربية الإسلامية بين التنظير والتطبيق، في

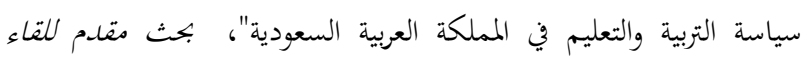

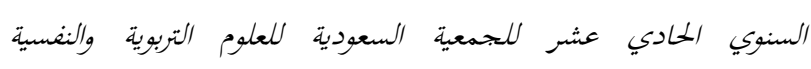

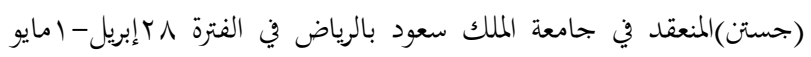
. T... عسليمان بن عبد الرممن الحقيل، نظام وسياسة التعليم في المملكة

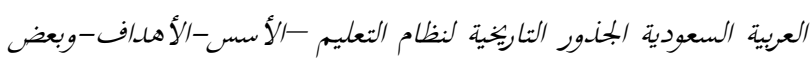

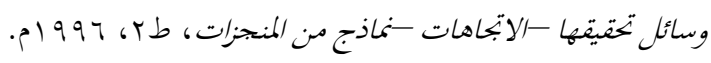


وضع أي نظام هو رضا الله سبحانه وتعالى وتحقيق دخول

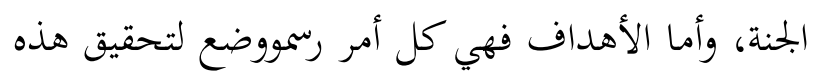

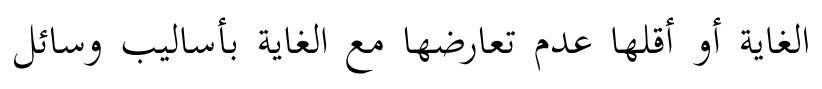
حضارية شرعية من مصادر أصلية لحاجة عصرية.

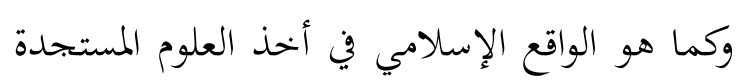

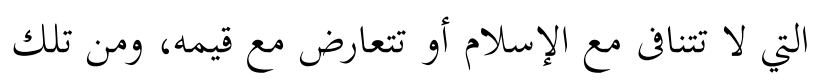

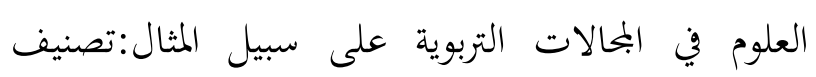

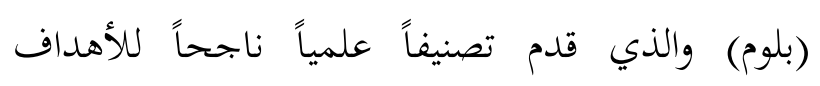

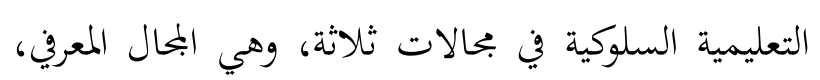

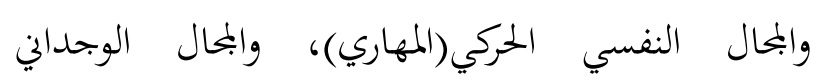

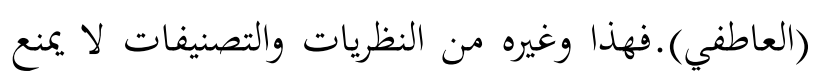
من أن يوظف في خدمة العملية والأنظمة التربوي الإسلامية.

أسس التربية الإسلامية إن أسس التربية الإسلامية لها خصوصية تميزها عن

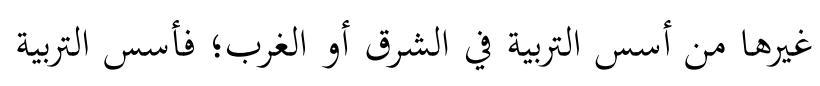

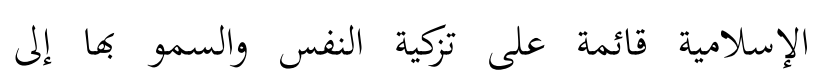

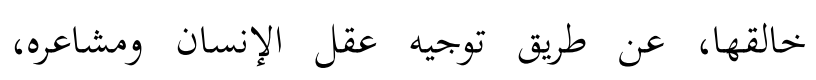
ليستدل بتأمل هذا الكون، وتأمل نفسه، على وجلى وجود الإنسان ومثاعره

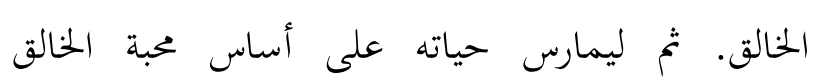

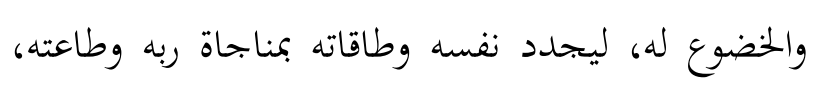

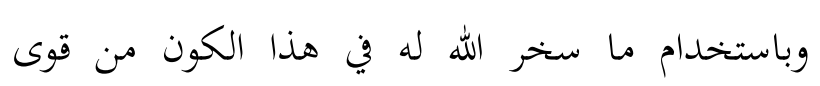
وكائنات، وهو يستهدف من ذلك كله تحقيق مرضاة الله،

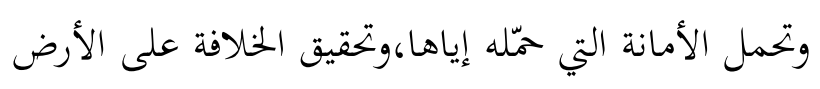

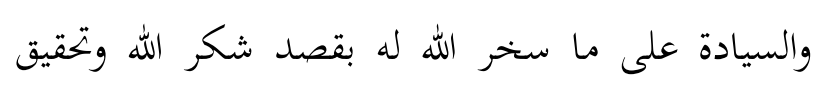
شريعته وعبادته، والدعوة إلى تحقيق هذه المعاني في سائر

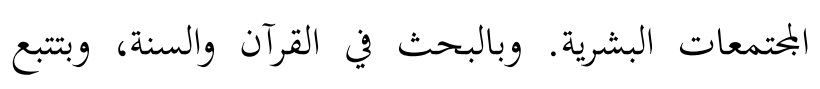
كيف ربى اللهسبحانه وتعالى الرسول صلى الله عليه
معرفياً فقط، بل يهدف إلى التطبيق العملي، والعلم وسيلة

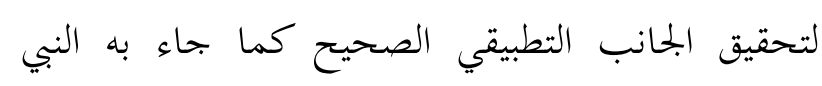
صلى الله عليه وسلم، فقال تعالى: هو الذي بعث في في لئحي

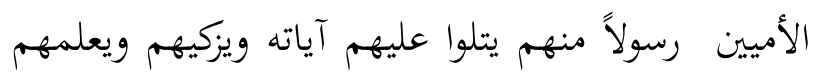
الكتاب والحكمة... ل.وفي تعريف لها بأها تجسيد الحقائق والمعطيات للإنسان وفق رؤية الإسلام للكون والحياة والإنسان والمصير 1.

\section{مصادر نظام التربية الإسلامية وخصائصها}

وبحكم أن دستور المملكة هو الكتاب والسنة، فإن مصادر نظام التربية الإسلامية هي من هذين المصدرين

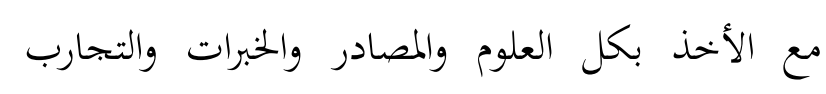

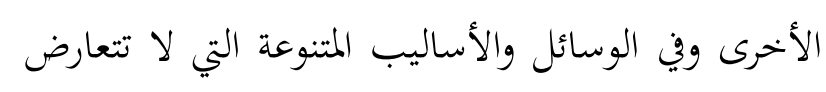

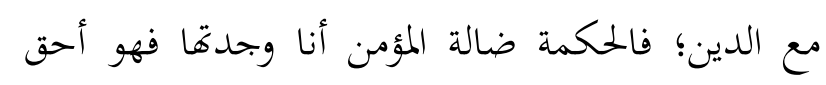

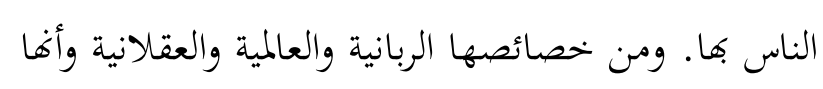

دائمة ومستمرة ومتوازنة وواقعية .

\section{الأهداف من نظام للتربية الإسلامية}

هناك فرق بين الغاية وبين الأهداف، فالغاية هي

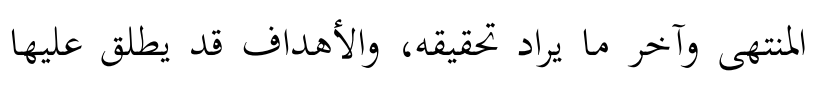

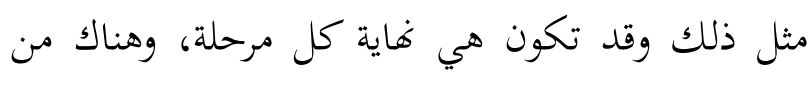

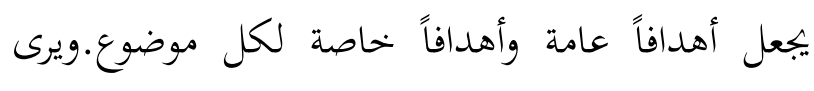
الباحث أن الغاية التي ينبغي أن توضع في الحسبان عاصنان عند

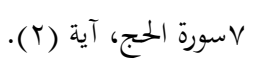

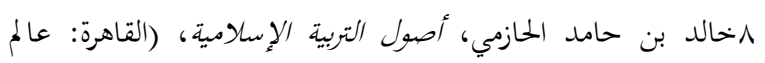

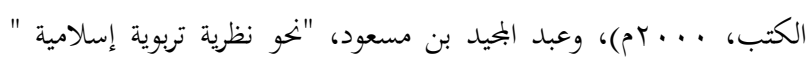

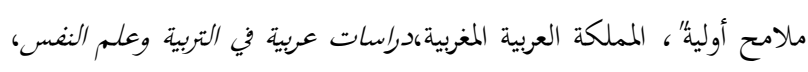

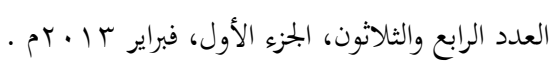

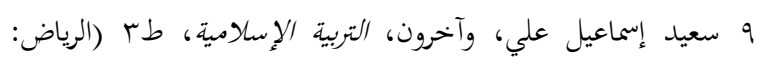

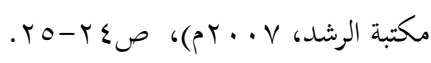


عقيدة الإسلام، وتُطبق شريعته، وتأمر بالمعروف وتنهى عن المنكر، وتقوم بواجب الدعوة إلى الله). والمتأمل في المواد السابقة يعرف بأن الإسلام هو المصدر الأساسي الذي يشتق منه التعليم أهدافه؛ فالعقيدة الإسلامية بمنهجها الشامل للإنسان والكون،

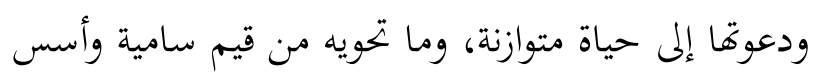

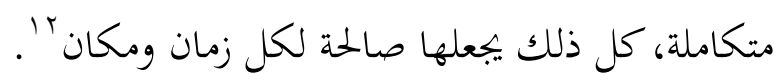
وإن الغاية في ذلك هيفهم الإسلام فهما صحيحا متكاملا، وغرس العقيدة ونشرها، وتزويد الطالب بالقيم والتعاليم الإسلامية والمثل العليا، وإكسابه المعارف

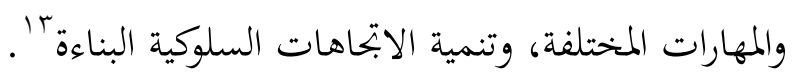

\section{الأسس التي تقوم عليها التربية}

وقبل الحديث عن تلك الأسس فإن الباحث سيشير هنا إلى ما حققه التعليم في المملكة، منذ بدء تأسيسه بصورة نظامية عام ع ع آهـ، من إبحازات كبيرة، ومنها: () توفر التعليم المحاني للجميع في كافة مراحله

$$
\text { وأنواعه. }
$$

ب) نشر التعليم في جميع أنحاء الوطن وتأمين جميع تكاليفه بحانًا.

r) ارتفاع نسبة الملتحقين بالمرحلة الابتدائية إلى

$$
\text { \%99\% من الفئة المستهلدفة. }
$$

ع) تحقيق المساواة بين الجنسين في فرص التعليم المتاحة.

ه) انخفاض نسبة الأمية بين الرجال والنساء. \&!

rا ب عبدالعزيز بن عبد الله السنبل وآخرون، نظام التعليم في المملكة

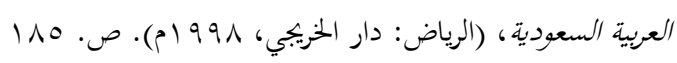

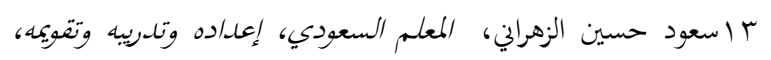

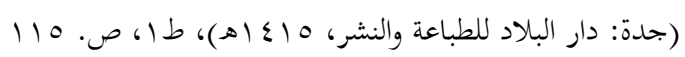

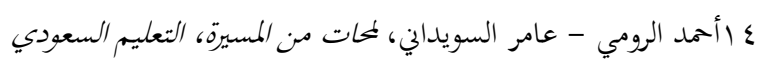

وسلم وعلى أي أساس ربى الرسول صلى الله عليه وسلم نفوس أصحابه وطهرها وزكاها، لوجدنا أن أهم الأسس الس اله التي ترتكز عليها التربية الإسلامية هيالأساس الاعتقادي

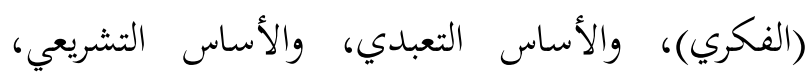
والأساس العلمي. '.

\section{أساس النظام في المملكة}

إن ما يميز النظام الذي تقوم عليه المملكة هو الأساس المتين الذي، يستمد من الإسلام عقيدة وشريعة، وقد جاء في المادة الأولى من هذا النظام: "المملكة دولة عربية إسلامية، ذات سيادة تامة، دينها الإسلام، ودستورها كتاب الله تعالى وسنة رسوله، ولغتها هي اللغة العربية، وعاصمتها مدينة الرياض 'ا"."كما جاء في المادة السابعة: "يستمد الحلكم في المملكة، من كتاب الله تعالى وسنة رسوله صلى الله عليه وسلم وهما الحاكمان على هذا النظام، وجميع أنظمة الدولة". وفيما يخص التعليم فقد جاء في المادة س ا: (يهدف التعليم إلى غرس العقيدة الإسلامية في نفوس النشء، وإكسابهم المعارف والمهارات وتهيئتهم ليكونوا أعضاء نافعين في بناء بحتمعهم، محبين لوطنهم، معتزين بتاريخه).أما المادة بr فقد جاء فيها: (تحمي الدولة • اعبد الرمن النحلاوي، أصول التربية الإسلامية وأساليبها في البيت

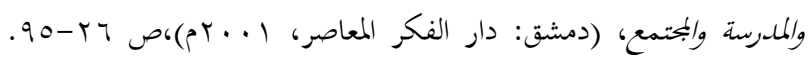

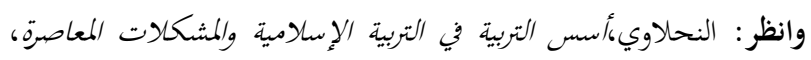

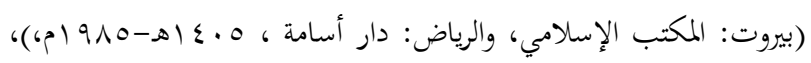
ص . .

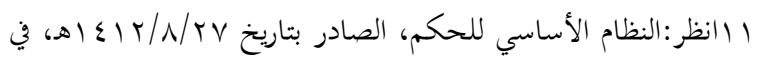

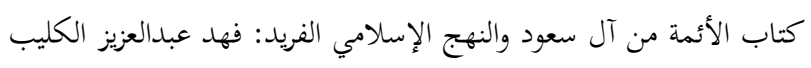

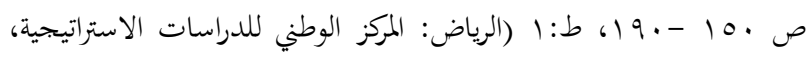

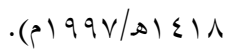


وفي شأن الأسس الأساسية العامة للتعليم في الأسس العامة التي يقوم عليها التعليم

1) الإيمان بالله ربّا وبالإسلام دينا وبمحمد صلى الله

$$
\text { عليه وسلم نبيَّا ورسولاً. }
$$

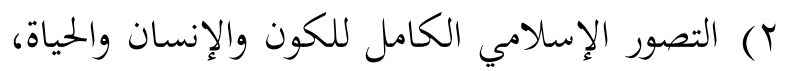

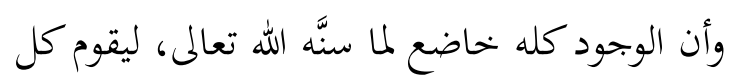
مخلوق بوظيفته دون خلل أو اضطراب. r المسلم طاقاته عن إيمان وهدى للحياة الأبدية الخالدة في الدار الآخرة، فاليوم عمل ولا حساب، وهدى لهابه الابدية

$$
\text { وغداً حساب ولا عمل. }
$$

ع) الرسالة المحمدية هي المنهج الأقوم للحياة الفاضلة التي تحقق السعادة لبني الإنسان، وتنقذ البشرية مُّّا

$$
\text { تردت فيه من فساد وشقاء. }
$$

0) المثل العليا التي جاء بهاء فئ الإسلام لقيام حضارة إنسانية رشيدة بناءة تمتدي برسالة محمد الإسلام صلى الله عليه وسلَّم، لتحقيق العزَّة في الدنيا،

$$
\text { والسعادة في الدار الآخرة. }
$$

7) الإيمان بالكرامة الإنسانية التي قرها القرآن الكريم

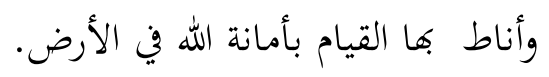

(V

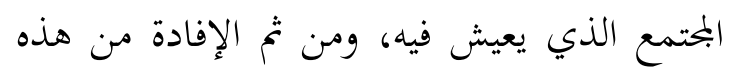

$$
\text { التنمية التي شارك فيها. }
$$

م) تقرير حق الفتاة في التعليم بما يلائم فطرقا ويعدها

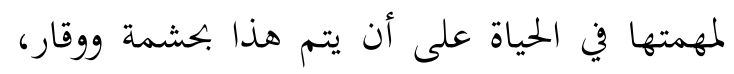

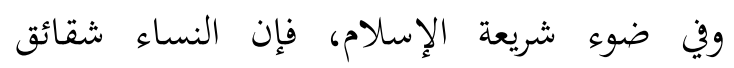

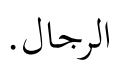
المملكة فقد تضمنت العديد من النقاط المهمة التي تحكم وتسير التعليم لما تتصف به من شمول يحقق أهداف التربية الإسلامية وغايتها وملاءمة الواقع والحاجة إليه ومراعاة

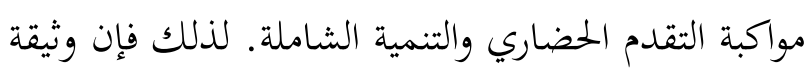
التعليم الصادرة من اللجنة العليا لسياسة التعليم عام

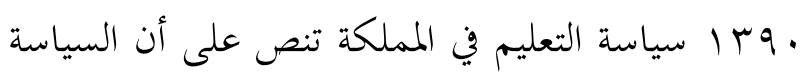
التعليمية هي الخطوط العامة التي تقوم عليها عملية التربية والتعليم أداء للواجب في تعريف الفرد بربه، ودينه، وإقامة سلوكه على شرعه، وتلبية للحاجات البحتمع،وتحقيقاً لأهداف الأمة. وهي تشمل حقول التعليم ومراحله

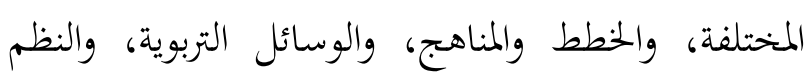
الإدارية والأجهزة القائمة على التعليم وسائر ما يتصل به.

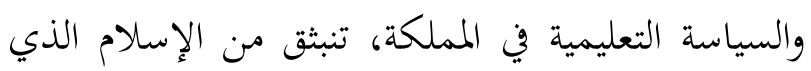

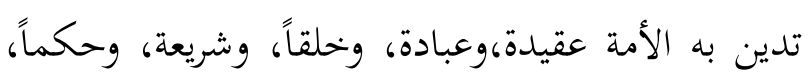

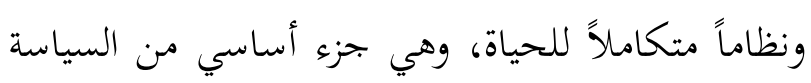

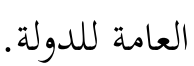
وفيما يلي عرض للأسس العامة التي يقوم عليها

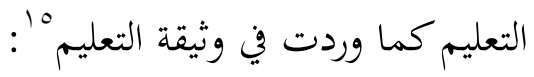

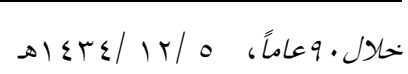

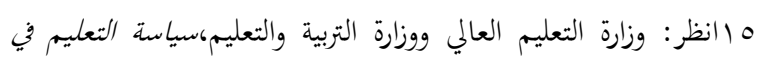

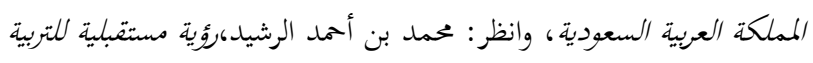

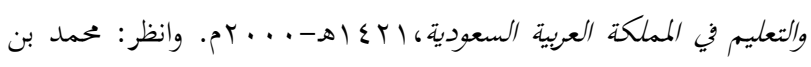

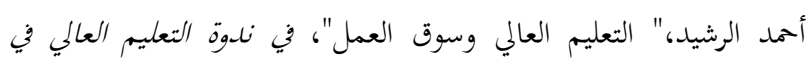

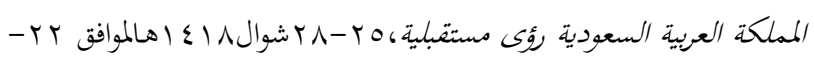

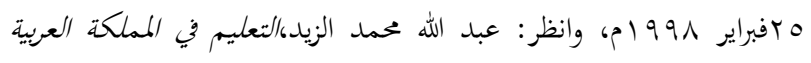

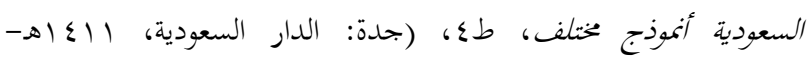

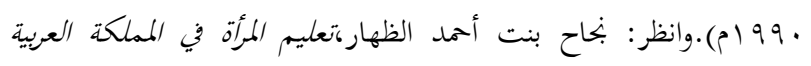

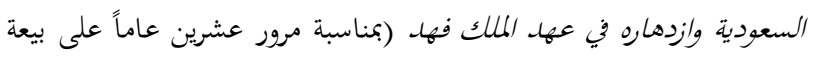

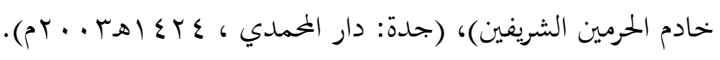


( V V الثقة الكاملة بمقومات الأمة الإسلامية وأخها خير

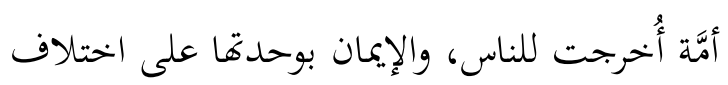

$$
\text { أجناسها وألواها وتباين ديارها. }
$$

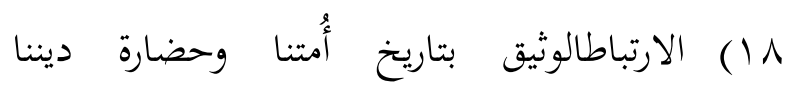

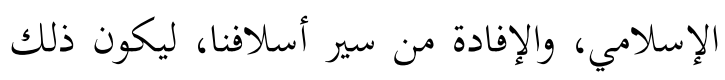
نبراساً لنا في حاضرنا ومستقبلنا.

19 التضامن الإسلامي في سبيل جمع كلمة المسلمين

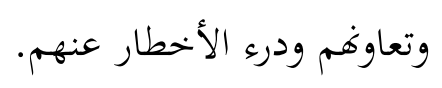

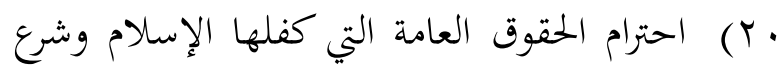

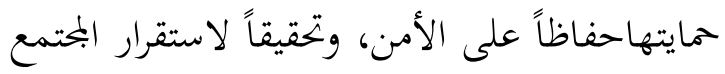

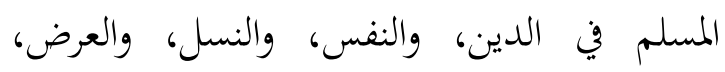
والعقل، والمال.

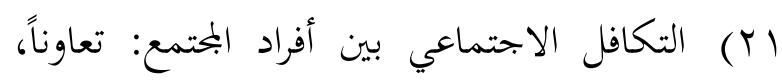

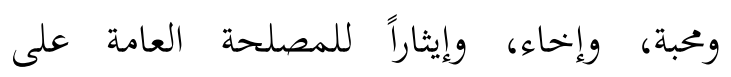
المصلحة الخاصة. r Y T النصح المتبادل بين الراعي والرعية بما يكفل المقاصل الحقوق والواجبات، وينمي الولاء والإخلاص.

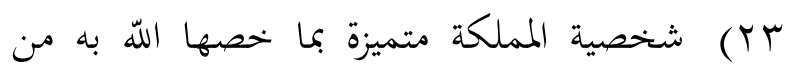
حراسة مقدسات الإسلام وحفاظها على مهبط

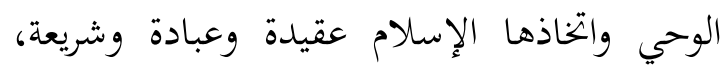

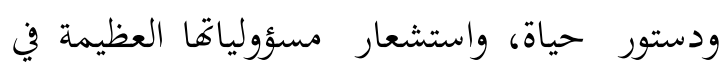

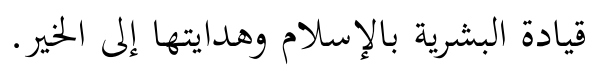

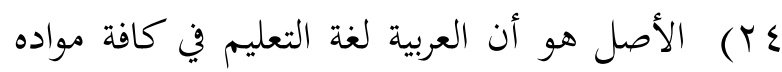

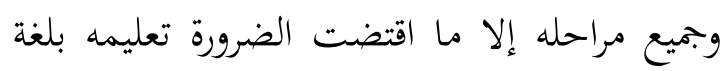
أُخرى. PO الدعوة إلى الإسلام في مشارق الأرض ومغارهما

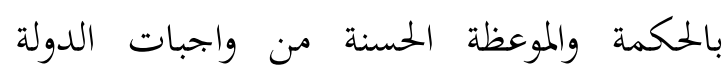

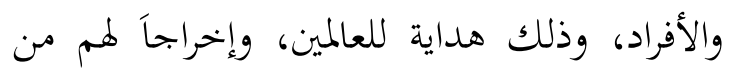

9) طلب العلم فرض على كل فرد بحكم الإسلام،

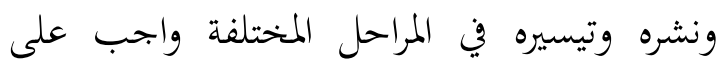
الدولة بقدر وسعها وإمكانياتما. • 1 ) العلوم الدينية أساسية في جميع سنوات التعليم الابتدائي و والمتوسط والثانوي بفروعه، والثقافة الإسلامية مادة أساسية في جميع سنوات التعليم العالي. 11) توجيه العلوم والمعارف بمختلف أنواعها وموادها

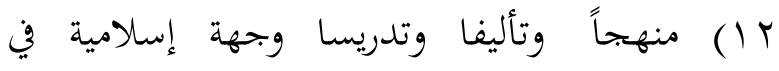
معالجة قضاياها والحكم على نظرياةا وطرق

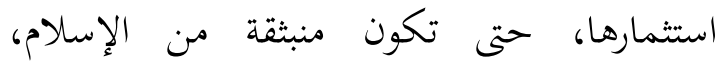
متناسقة مع التفكير الإسلامي السديد. r ا ) الاستفادة من جميع أنواع المعارف الإنسانية

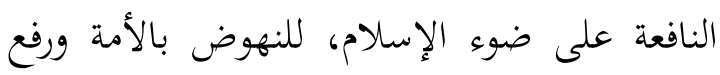
مستوى حياتما، فالحكمة ضالة المؤمن أنى وجدها لإلها

$$
\text { فهو أولى الناس بها. }
$$

ع 1) التناسق المنسجم مع العلم والمنهجية التطبيقية

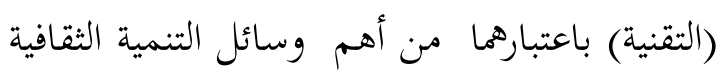
والاجتماعية والاقتصادية والصحية، لرفع مستوى أمتنا وبلادنا، والقيام بدورنا في التقدم الثقافي الثيا

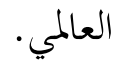
ه 1) ربط التربية والتعليم في جميع المراحل بخطة التنمية

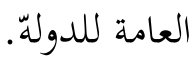
1 (1) التفاعل الواعي مع التطورات الحضارية العالمية في

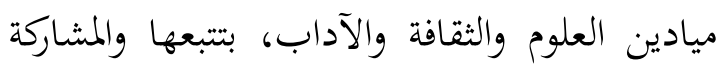

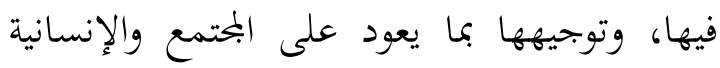

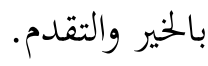


الظلمات إلى النور، وارتفاعا بالبشر في بحال ع تحقيق الخلق القرآني في المسلم والتأكيد على الضوابط الخلقية لاستعمال المعرفة: "إنَّا بُعثتُ لأتمّم العقيدة إلى مستوى الفكر الإسلامي. مكارِمَ الأخْلاقِ". 0) تربية المواطن المؤمن ليكون لبنة صالحة في بناء أُمته، ويشعر بمسؤولياته لخدمة بلاده والدفاع عنها. 7) تزويد الطالب بالقدر المناسب من المعلومات الثقافية والخبرات المختلفة التي تجعل منه عضواً

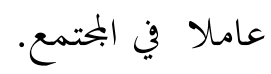

V تنمية إحساس الطلاب بمشكلات البحتمع الثقافية

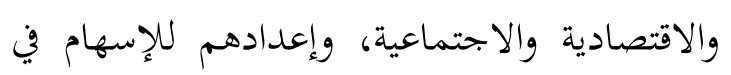
حلها.

^) تأكيد كرامة الفرد وتوفير الفرص المناسبة لتنمية قدراته حتى يستطيع المساهمة في هضة الأمة. 9) دراسة ما في هذا الكون الفسيح عن عظيم الخلق، وعجيب الصنع، واكتشاف ما ينطوي عليه في أسرار قدرة الخالق للاستفادة منها وتسخيرها لرفع كيان الإسلام لما وإعزاز أمته.

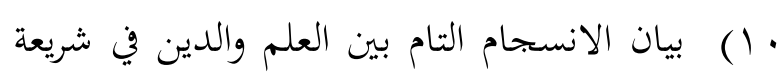

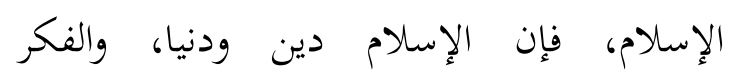
الإسلامي يفي بمطالب الحياة البشرية في أرقى صورها في كل عصر. 11) تكوين الفكر الإسلامي المنهجي لدى الأفراد،

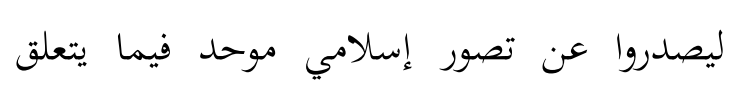

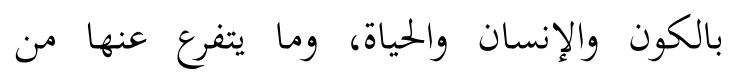
وغاية التعليم هي فهم الإسلام فهما صحيحا

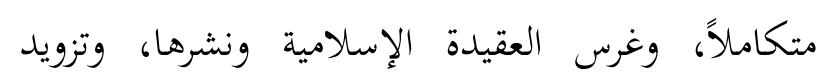
الطالب بالقيم والتعاليم الإسلامية وبالمثل العليا، وإكسابه المعارف والمهارات المختلفة، وتنمية الاتحاهات السلوكية البناءة، وتطوير المجتمع اقتصاديا واجتماعيًّا وثقافيا، وتهيئة الفرد ليكون عضواً نافعا في بناء بحتمعه. والأهداف الإسلامية العامة التي تحقق غاية التعليم

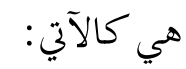
1) تنمية روح الولاء لشريعة الإسلام، وذلك بالبراءة

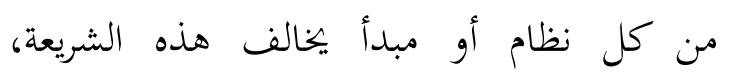
واستقامة الأعمال والتصرفات وفق أحكامها العامة الشاملة. Y) النصيحة لكتاب الله وسنة رسوله بصيانتهما، ورعاية حفظهما، وتعهد علومهما، والعمل بما جاء تفصيلات. Y I ) رفع مستوى الصحة النفسية بإحلال السكينة في نفس الطالب،وتهيئة الجو المدرسي المناسب. ץ) تزويد الفرد بالأفكار والمشاعر والقدرات اللازمة

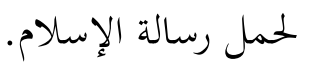




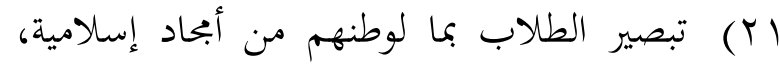

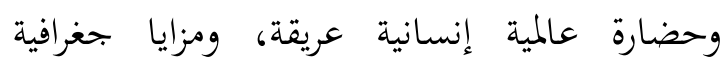
وطبيعية واقتصادية، وبما لمكانته من أهمية بين أمم وحنماريا

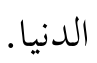

Tr T الطهم البيئة بأنواعها المختلفة، وتوسيع آفاق الطلاب بالتعرف على مختلف أقطار العالم وما

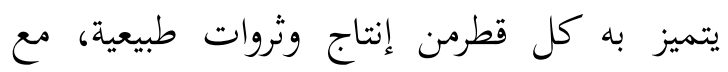
التأكيد على ثروات بلادنا ومواردها الخام، ومركزها الجغرافي، والاقتصادي، ودورها السياسي القيادي لريات في الحفاظ على الإسلام، والقيام بواجب دعوته،

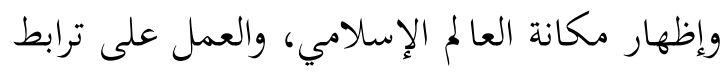

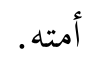

rrr تزويد الطلاب بلغة أخرى من اللغات الحية على انلى

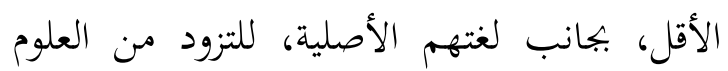

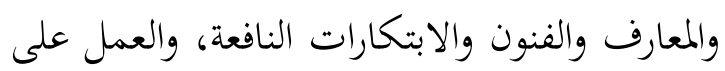

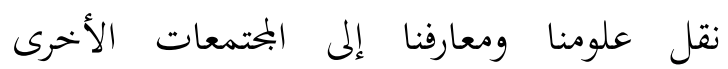
وإسهاما في نشر الإسلام وخدمة الإنسانية. §؟) تعويد الطلاب العادات الصحية السليمة، ونشر

$$
\text { الوعي الصحي. }
$$

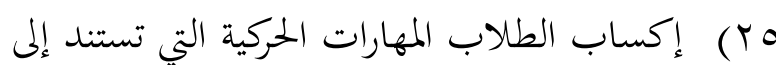
القواعد الرياضية والصحية لبناء الجسم السليم،

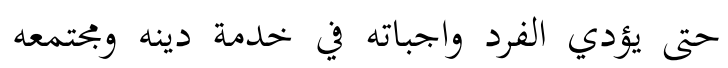
بقوة وثبات.

צr) مسايرة خصائص مراحل النمو النفسي للناشئين في كل مرحلة، ومساعدة الفرد على النمو السوي:

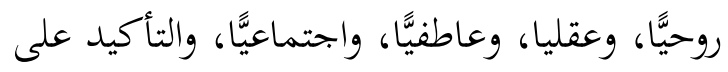

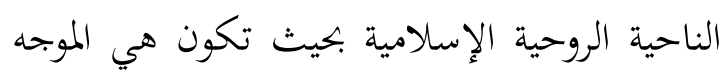
الأول للسلوك الخاص والعام للفرد والبحتمع. r ا ) تشجيع وتنمية روح البحث والتفكير العلميين،

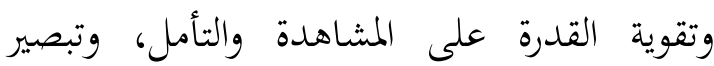

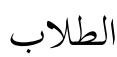

ع ا) بآيات اللّ في الكون وما فيه، وإدراك حكمة اللّ في خلقه لتمكين الفرد من الاضطلاع بدوره الفعال في بناء الحياة الاجتماعية وتوجيهها توجيهاً سليماً. 10) الاهتمام بالإنحازات العالمية في ميادين العلوم والآداب والفنون المباحة، وإظهار أن تقدم العلوم ثمرة لجهود الإنسانية عامة، وإبراز ما أسهم به أعلام

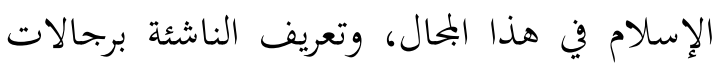
الفكر الإسلامي، وتبيان نواحي آلابتكار في آرائهم وأعمالهم في مختلف الميادين العلمية والعملية. 1 (1) تنمية التفكير الرياضي والمهارات الحسابية، والتدرب على استعمال لغة الأرقام والإفادة منها في البحالين العلمي والعملي. تنمية مهارات القراءة وعادة المطالعة سعياً وراء (IV زيادة المعارف.

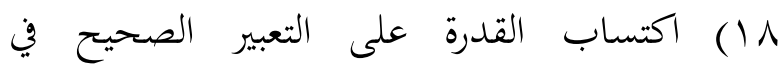
التخاطب والتحدث والكتابة بلغة سليمة وتفكير اكتياب التعدرة منظَّم. 9 1) تنمية القدرة اللغوية بشتى الوسائل التي تغذي

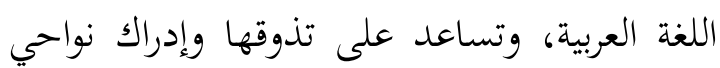
الجمال فيها أسلوبا وفكرة.

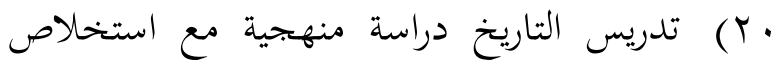

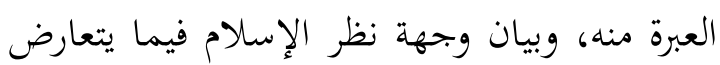

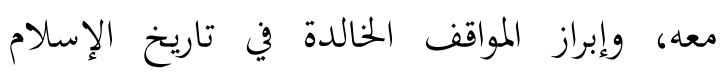

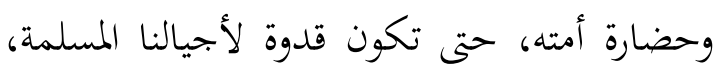
تولد لديها الثقة والإيجابية. 
ث- إقامة الصلات الوثيقة التي تربط بين أبناء الإسلام وتبرز وحدة أمته.

$$
\text { أهداف التعليم الابتدائي: }
$$

(1) تعهد العقيدة الإسلامية الصحيحة في نفسه الطفل

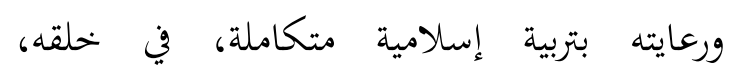
وجسمه، وعقله، ولغته، وانتمائه إلى أمة الإسلام.

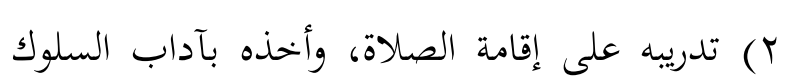

$$
\text { والفضائل. }
$$

r) تنمية المهارات الأساسية المختلفة وخاصة المهارة اللغوية، والمهارة العددية، والمهارات الحركية.

ع) تزويده بالقدر المناسب من المعلومات في مختلف ولف المهديه الموضوعات.

0) تعريفه بنعم الله عليه في نفسه، وفي بيئته الاجتماعية

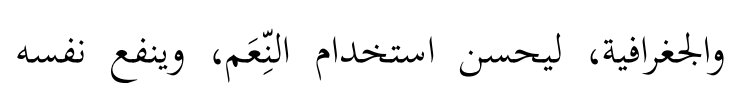

$$
\text { وبيئته. }
$$

ج) تربية ذوقه البديعي، وتعهد نشاطه الابتكاري،

$$
\text { وتنمية تقدير العمل اليدوي لديه. }
$$

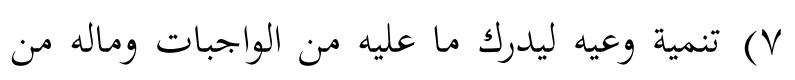
الحقوق، في حدود سنّه وخصائص المرحلة التي يمر

$$
\text { بها، وغرس حب وطنه، والإخلاص لولاة أمره. }
$$

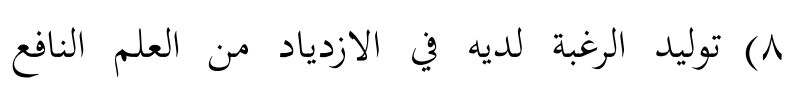
والعمل الصالح، وتدريبه على الاستفادة من أوقات لرئل

$$
\text { فراغه. }
$$

9) إعداد الطالبلما يلي هذه المرحلة من مراحل

حياته.

\section{المرحلة المتوسطة وأهدافها}

المرحلة المتوسطة مرحلة ثقافية عامة، غايتها تربية الناشئ تربية إسلامية شاملة لعقيدته وعقله وجسمه
(TV

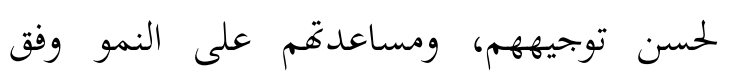
قدراهم واستعداداهم وميولمم.

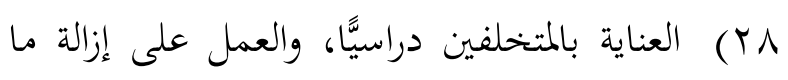
يمكن إزالته من أسباب هذا التخلف، ووضع برامج خاصة دائمة ومؤقتة وفق حاجاهم. 9 Y التربية الخاصة والعناية بالطلاب المعوقين جسميًّا أو عقلياً، عملاً بهدي الإسلام الذي يجعل التعليم حما مشاعا بين جميع أبناء الأمة. •r. الإمكانيات والفرص المختلفة لنمو مواهبهم في إطار البرامج العامة، وبوضع برامج خاصة. ابr) تدريب الطاقة البشرية اللازمة، وتنويع التعليم مع الاهتمام الخاص بالتعليم المهني.

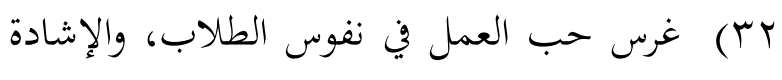
به في سائر صوره، والحض على إتقانه والإبداع فيه، والتأكيد على مدى أثره في بناء كيان الأمة، ويستعان على ذلك بما يلي: أـ تكوين المهارات العلمية والعناية بالنواحي التطبيقية في المدرسة، بحيث يتاح للطالب الفرصة للقيام بالأعمال الفنية اليدوية، والإسهام في الإنتاج، وإجراء التجارب في المخابر والورش والحقول. ب- - دراسة الأسس العلمية التي تقوم عليها الأعمال المختلفة، حتى يرتفع المستوى الآلي لإنتاج إلى

$$
\text { مستوى النهوض والابتكار. }
$$

ت- إيقاظ روح الجهاد الإسلامي لمقاومة أعدائنا، واسترداد حقوقنا، واستعادة أبحادنا، والقيام بواجب رسالة الإسلام. 
وهي تستدعي ألوانا من التوجيه والإعداد، وتضمٌّ فروعا مختلفة يلتحق بها حاملو الشهادة المتوسطة وفق الأنظمة التي تضعها الجهات المختصة، فتشمل: الثانوية العامة، وثانوية المعاهد العلمية، ودار التوحيد، و والجامعة الإسلامية، ومعاهد إعداد المعلمين والمعلمات، والمعاهد المهنية بأنواعها المختلفة (من زراعية وصناعية وبتحارية)،

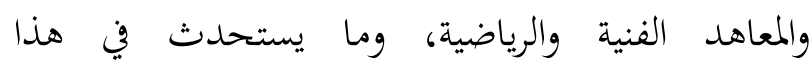
المستوى.وهذه المرحلة تشارك غيرها من المراحل في تحقيق الأهداف العامة للتربية والتعليم، بالإضافة إلى ما تحققه من أهدافها الخاصة. وأهداف المرحلة الثانوية :

( ) متابعة تحقيق الولاء لله وحده، وجعل الأعمال خالصة لوجهه، ومستقيمة- في كافة جوانبها-

$$
\text { على شرعه. }
$$

r) دعم العقيدة الإسلامية التي تستقيم بها نظرة الطالب إلى الكون والإنسان والحياة في الدنيا والآخرة، وتزويده بالمفاهيم الأساسية والثقافية

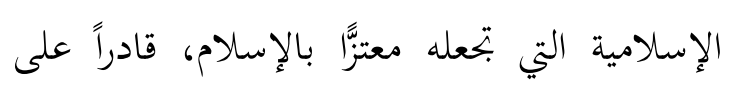

$$
\text { الدعوة إليه، والدفاع عنه. }
$$

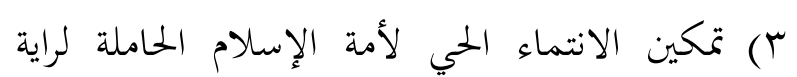

$$
\text { التوحيد. }
$$

ع) تحقيق الوفاء للوطن الإسلامي العام، وللوطن الخاص (المملكة)، بما يوافق هذه السن، من تسام في الأفق، وتطلع إلى العلياء، وقوة في الجحسم. 0) تعهد قدرات الطالب، واستعداداته المختلفة التي تظهر في هذه الفترة، وتوجيهها وفق ما يناسبه وما يحقق أهداف التربية الإسلامية في مفهومها العام.
وخلقه، يراعى فيها نمؤه وخصائص الطور الذي يمرٌ به، وهي تشارك غيرها في تحقيق الأهداف العامة من التعليم. وأهداف التعليم المتوسط:

(1) تمكين العقيدة الإسلامية في نفس الطالب وجعلها ضابطة لسلوكه وتصرفاته، وتنمية محبة الله وتقواه وخشيته في قلبه.

r) تزويده بالخبرات والمعارف الملائمة لسنِّه، حتى يلمَّم بالأصول العامة والمبادئ الأساسية للثقافة والعلوم. ץ) تشويقه إلى البحث عن المعرفة، وتعويده التأمل والتتبع العلمي. §) تنمية القدرات العقلية والمهارات المختلفة لدى وليع الطالب، وتعهدها بالتوجيه والتهذيب. 0) تربيته على الحياة الاجتماعية الإسلامية التي يسودها الإخاء والتعاون، وتقدير التبعة، وتحمل

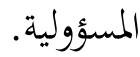

7) تدريبه على خدمة بحتمعه ووطنه، وتنمية روح النصح والإخلاص لولاة أمره.

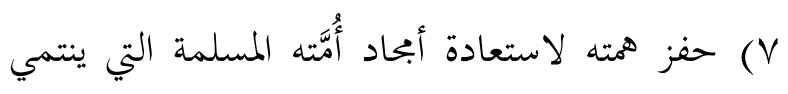
إليها، واستئناف السير في طريق العزة والمحد. ^) تعويده الانتفاع بوقته في القراءة المفيدة، واستثمار فراغه في الأعمال النافعة، وتصريف نشاطه بما يجعل شخصيته الإسلامية مزدهرة قوية. 9) تقوية وعي الطالب ليعرف بقدر سنهيف يواجه الإشاعات المضللة، والمذاهب الهدامة، والمبادئ

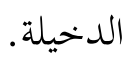
• (1 إعداده لما يلي هذه المرحلة من مراحل الحياة. أهداف المرحلة الثانوية،للمرحلة الثانوية طبيعتها الخاصة من حيث سن الطلاب وخصائص نموهم فيها، 
لمواهبهم، وسلَّا لحاجات المجتمع المختلفة في حاضرة

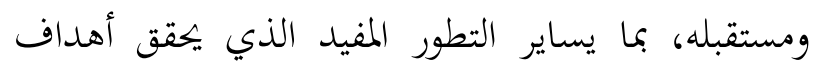

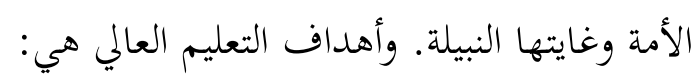

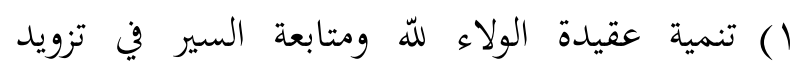
الطالب بالثقافة الإسلامية التي تشعره بمسؤولياته أمام اللّ عن أمة الإسلام لتكون إمكانياته العلمية

$$
\text { والعملية نافعة مثمرة. }
$$

Y) إعداد مواطنين أكفاء مؤهلين علميا وفكريَّا

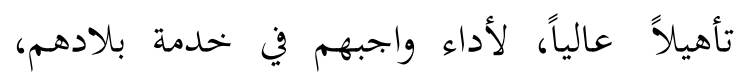

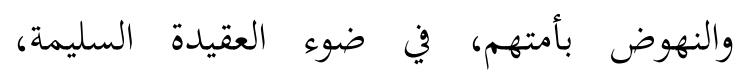

$$
\text { ومبادئ الإسلام السديدة. }
$$

r) إتاحة الفرصة أمام النابغين للدراسات العليا في الإهات

$$
\text { التخصصات العلمية المختلفة. }
$$

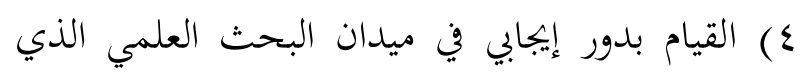

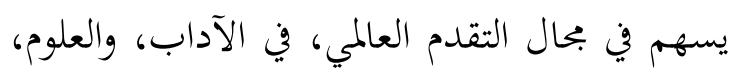
والمخترعات وإيجاد الحلول السليمة الملائمة لمتطلبات الحياة المتطورة واتحاهاتا التقنية (التكنولوجية).

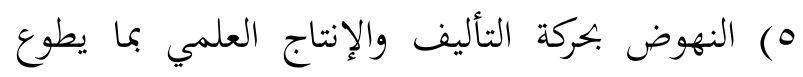
العلوم لخدمة الفكرة الإسلامية، ويمكن البلاد من دورها القيادي لبناء الحضارة الإنسانية على مبادئها

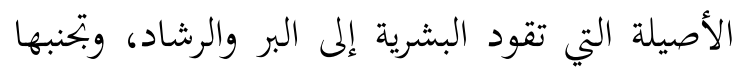

$$
\text { الانخرافات المادية والإلحادية. }
$$

7) ترجمة العلوم وفنون المعرفة النافعة إلى لغة القرآن،

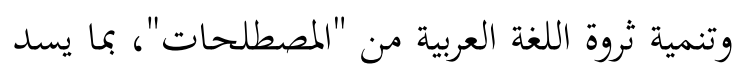
حاجة التعريب، ويبعل المعرفة في متناول أكبر عدد من المواطنين.

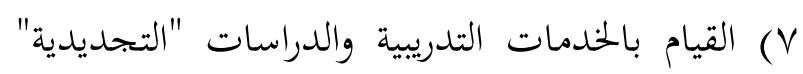

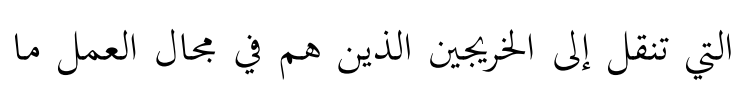

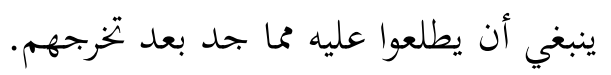

7) تنمية النفكير العلمي لدى الطالب، وتعميق روح

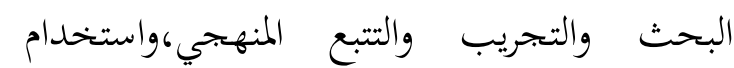
المراجع، والتعوُّد على طرق الدراسة السليمة.

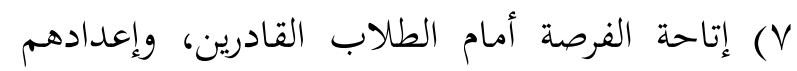

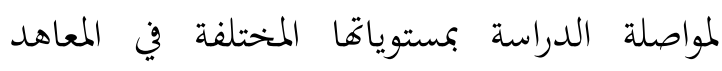
العليا، والكليات الجامعية، في مختلف التخصصات.

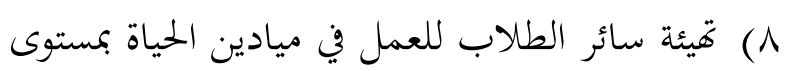
لائق. 9) تخريج عدد من المؤهلين مسلكيا وفنيا لسد حاجة البلاد في المرحلة الأولى من التعليم، والقيام بالمهام

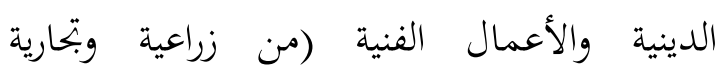
وصناعية) وغيرها. • (1) متقيق الوعي الأسري لبناء أُسرة إسلامية سليمة.

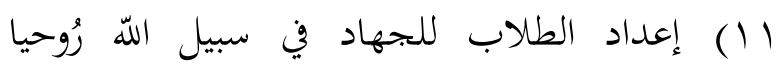
وبدنيًّا. r (I ) رعاية الشباب على أساس الإسلام، وعلاج

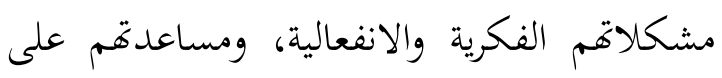
اجتياز هذه الفترة الحرجة من حياقم بنجاح وسلام. r ا ) إكساهمم فضيلة المطالعة النافعة والرغبة في الازدياد من العلم النافع والعمل الصالح، واستغلال

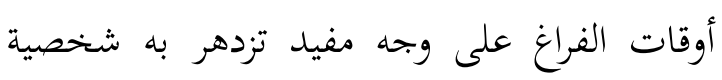

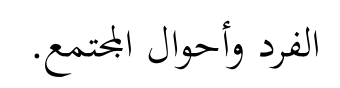

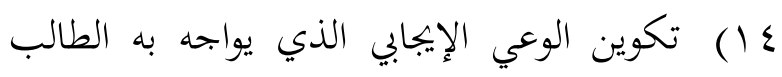
الأفكارَ الهدامة والاتحاهاتِ المضللة.

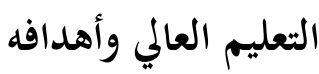

التعليم العالي هو مرحلة التخصص العملي في كافة

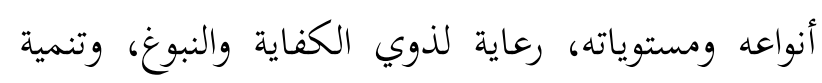


Y (الدراسة في المرحلة الثانوية متنوعة، وهي متاحة التخطيط لمراحل التعليم

ما أمكن لحاملي الشهادة المتوسطة، وتضع التخطيط للمرحلة الابتدائية:

الجهات المختصة شروط القبول في كل نوع من

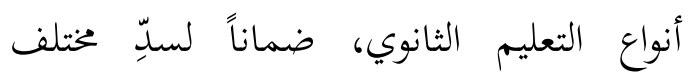
الحاجات، وتوجيه كل طالب لما يناسبه.

ץ) تفتح المدارس الثانوية- على مختلف أنواعهاوفق تخطيط مدروس تنسقه الجهات التعليمية، وتراعى فيه الحاجات والإمكانيات وطبيعة المنطقة.

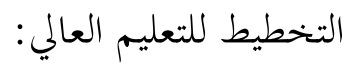

( ) التعليم العالي يبدأ بعد الثانوية العامة أو ما يعادلها. ب) يخضع التعليم العالي- - حكوميا كان أو أهليَّابمختلف فروعه للمجلس الأعلى للتعليم. r تُنشأ الجامعات والكليات في المملكة بما يلائم حاجة البلاد و إمكانياتها.

ع) يكون للجامعات بحلس أعلى ويوضح نظامه واختصاصاته ومسؤولياته وطريقة عمله. 0) ينسق التعليم العالي بين الكليات المختلفة بشكل يحقق التوازن في احتياجات البلاد في مختلف

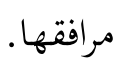

ד) تفتح أقسام للدراسات العليا في التخصصات المختلفة كلما توافرت الأسباب والإمكانيات

(V تمنح الجامعات الدرجات الجامعية للخريجين على

$$
\text { اختلاف مستوياةه. }
$$

^) تتعاون الجامعات في المملكة مع الجامعات الأخرى في البلاد الإسلامية لتحقيق أهداف أمة الإسلام

$$
\text { في بناء حضارة إسلامية أصيلة. }
$$

() مدة الدراسة في المرحلة المتوسطة ثلاث سنوات،تبدأ بعد نيل الشهادة الابتدائية، أو ما في مستواها، وتنتهي بنيل الشهادة المتوسطة. Y) الدراسة في المرحلة المتوسطة متاحة ما أمكن بكلئل لحاملي الشهادة الابتدائية. ب) يراعى فتح المدارس المتوسطة حيث يكثر حملة الشهادة الابتدائية، وبتعل المدرسة في مكان وسط مناسب ينقل إليه الطلاب من الأماكن

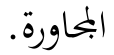
التخطيط للمرحلة الثانويّة: () مدة الدراسة في المرحلة الثانوية ثلاث سنوات،وتنتهي بنيل الشهادة الثانويةبأنواعها

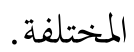


الإسلامية وعلوم اللغة العربية، وما ينشأ من الكليات لخدمة الشريعة واللغة العربية وشؤون الأمة الإسلامية. 0) تُعنى كلية الشريعة في هذه الجامعة بالدراسات الحقوقية لتخريج متخصصين شرعيين حقوقيين لسد حاجة البلاد. 7) تفتح الجامعة أبوابها لعدد مناسب من طلاب البلاد

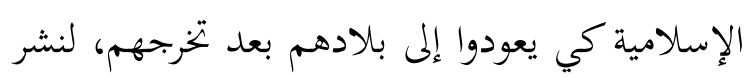
الإسلام والقيام بواجب دعوته.

V تقبل الجامعة الطلاب الذين تتوافر فيهم شروطها من حملة الشهادة الثانوية للمعاهد العلمية و دار التوحيد

$$
\text { أو ما يعادلما. }
$$

\section{كليات البنات}

تُنشأ كليات للبنات ما أمكن ذلك لسد حاجات

البلاد في بحال اختصاصهن بما يتفق والشريعة الإسلامية.

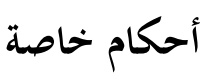

أ- - المعاهد العلمية

تواكب "المعاهد العلمية" النهضة التعليمية في البلاد،

وتشارك التعليم العام في مواد الدراسة المناسبة وتعنى عناية خاصة بالدراسات الإسلامية وفروع اللغة العربية. ويؤهل هذا النوع من التعليم الدارسين فيه للتخصصات في علوم

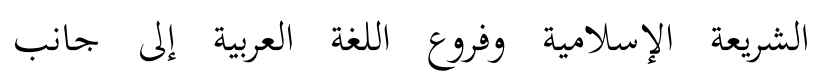

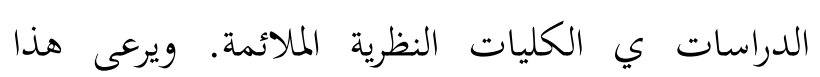

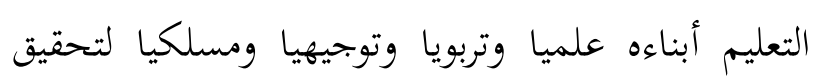

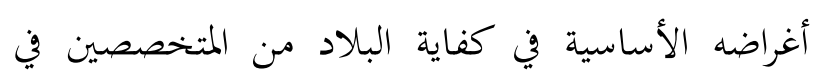
الشريعة الإسلامية وعلوم اللغة العربية والدعاة إلى الله .

$$
\text { ب- تعليم البنات }
$$

9) تتعاون الجامعات في المملكة مع الجامعات العالمية في الاهتمام بالبحوث العلمية والاكتشافات والمخترعات، واتخاذ وسائل التشجيع المناسبة، وتتبادل معها البحوث النافعة.

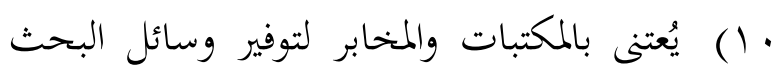

$$
\text { في التعليم العالي. }
$$

(1) (1) تُشأ دائرة للترجمة تتابع الأبحاث العلمية في كافة المواد، وتقوم بترجتها، لتحقيق تعريب التعليم

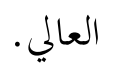

ب (1 ) يُدرس في الكليات الجامعية والمعاهد العالية تاريخُ

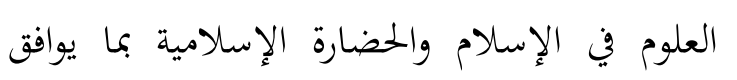
الجامعة الإسلامية اختصاص هذه المؤسسات، تعريفا لطلابها في ميادين اختصاصهم بما أبخزه المسلمون.

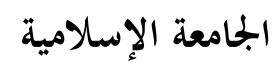

(1) تنشأ جامعة إسلامية كبرى للإعداد علماء متخصصين في العلوم الإسلامية وعلوم اللغة العربية، إحياءً للتراث الإسلامي، وعملاً على ازدهاره، وقياماً بواجب الدعوة إلى الإسلام. r) تخظى الجامعة الإسلامية برعاية خاصة لتكون مركز

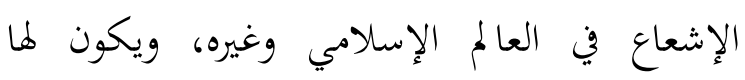
شخصية مستقلة ترتبط مباشرة بعاهل المملكة. r) تُعنى هذه الجامعة بالبحوث الإسلامية، وتقوم بترجمتها ونشرها، وتنظم العلاقة بينها وبين جامعات العالم لسد فراغ الدراسات الإسلامية والعربية. ع) تتكون الجامعة من الكليات ومعاهد التعليم الديني القائمة في المملكة المتخصصة في دراسة علوم الشريعة 
والتجارية والصناعية وغيرها. وتتخذ الجهات التعليمية

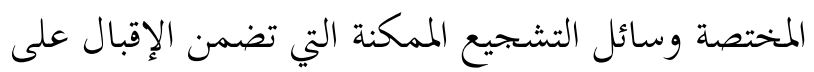

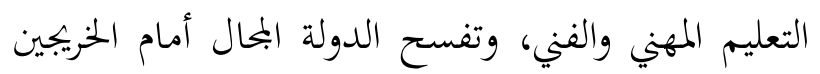

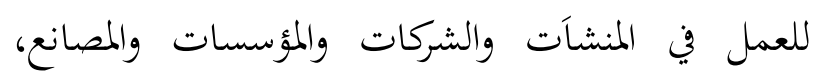
وتضع الوزارات النظام الكفيل بتشغيل الخريجين وتنظيم

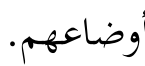

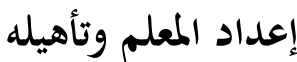

تكون مناهج إعداد المعلمين في مختلف الجهات التعليمية وفي جميع المراحل وافية بالأهداف الأساسية التي تنشدها الأمة في تربية جيل مسلم يفهم الإسلام فهما صحيحا، ويبذل جهده في النهوض بأمتّه. ويُعنى بالتربية الإسلامية واللغة العربية في معاهد وكليات إعداد المعلمين حتى يتمكنوا من التدريس بروح إسلامية عالية ولغة عربية

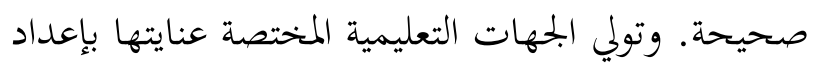

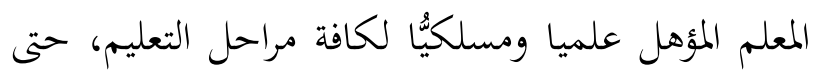
يتحقق الاكتفاء الذاتي، وفق خطة زمنية. وتتوسع الجهات

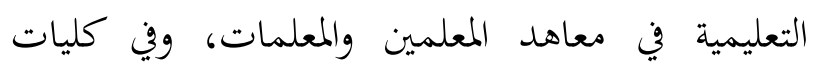

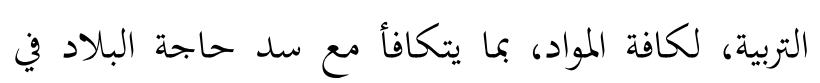

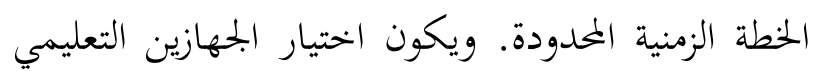

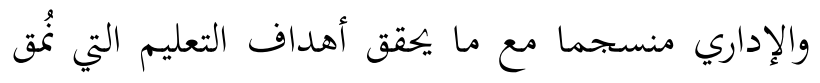

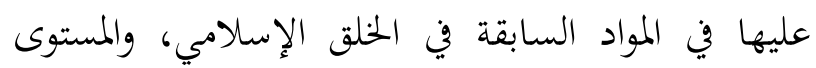

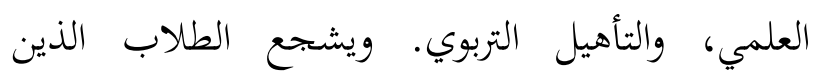

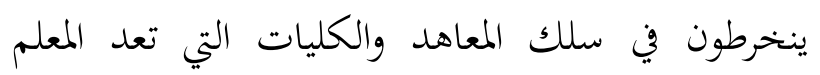

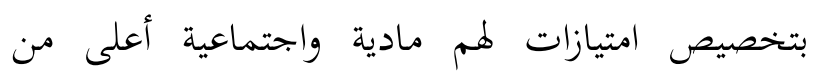

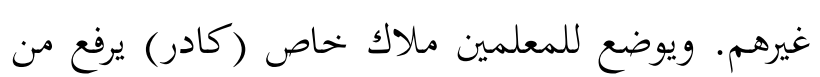

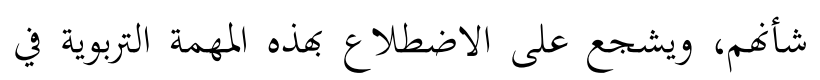

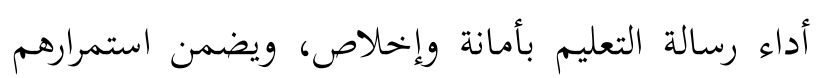

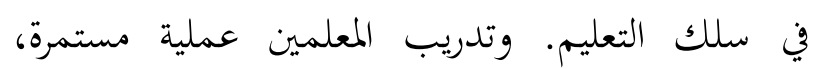

يستهدف تعليم الفتاة تربيتها صحيحه إسلامية

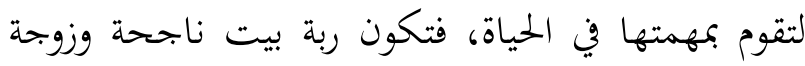

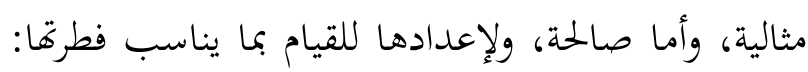
كالتدريس، والتمريض، والتطبيب. وتهتم الدولة بتعليم

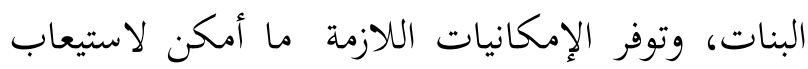

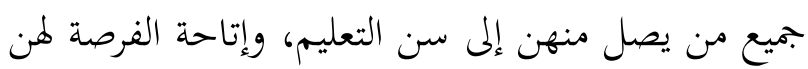

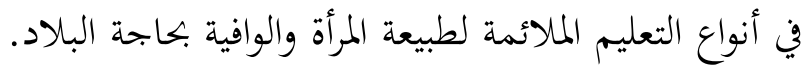
ويمنع الاختلاط بين البنين والبنات في جميع مراحل التعليم

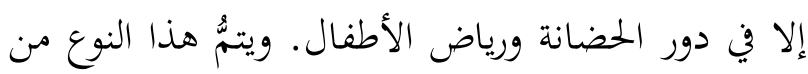

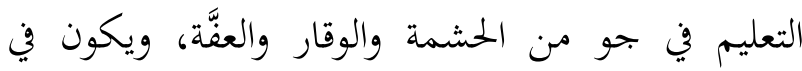
كيفيته وأنواعه متفقا مع أحكام الإسلام.

$$
\text { ت- - ت التعليم الفني }
$$

يهدف التعليم الفني إلى كفاية المملكة من العاملين

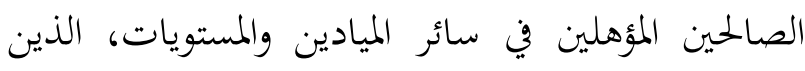
تتوافر فيهم العقيدة السليمة، والخلق الفاضل، وإتقان العمل، وحسن القيام بما يوكل إليهم من مهام. وتعنى

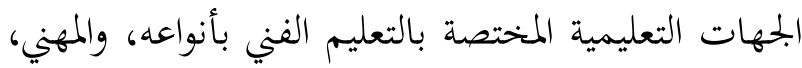

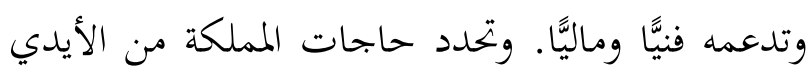

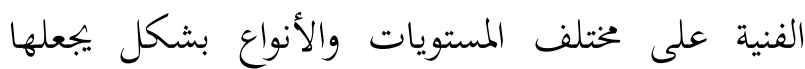

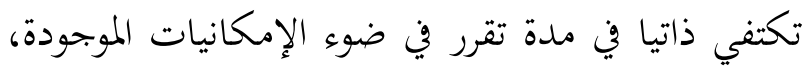

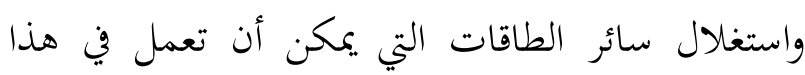

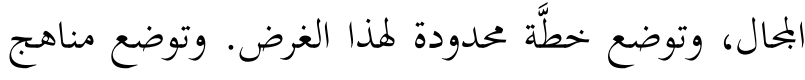
التعليم الفني والمهني وخطتها الدراسية بمايحقق أهدافها، ويراعى أن تكون متنوعة ومرنة لتواجه كافة الحاجات

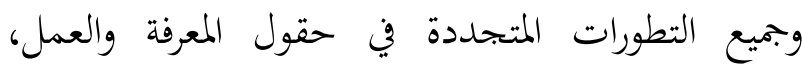

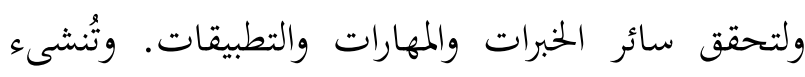

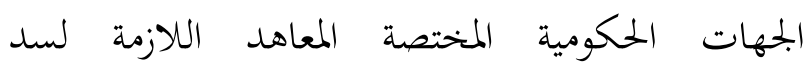
احتياجات المملكة من العاملين في الميادين الزراعية 
المدارس والمعاهد الأهلية خاص بالجهات التعليمية المختصة، ولا يسمح به لغير السعوديين. ويوضح نظام التعليم الأهلي الشروط التي يجب توافرها فيه، والواجبات

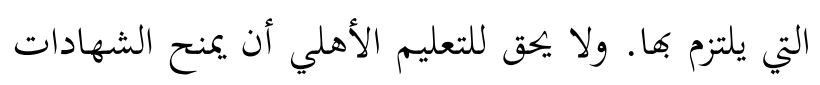

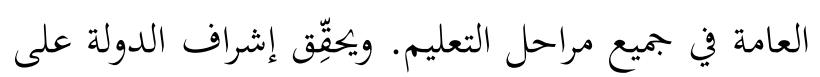
التعليم الأهلي الأهداف التالية: ( ) ضمان مستوى مناسب من التربية والتعليم والشروط الصحية لا يقل عن مستوى مدارس الدولة. r ) ضمان صحة ابتحاه المدرسة وفق مقتضيات الإسلام.

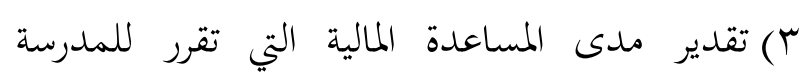
لتحقيق العدل والتوازن بين مختلف المدارس الأهلية.

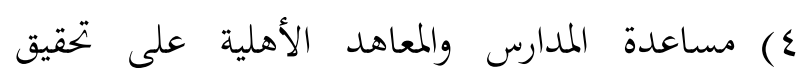
أهداف التربية والتعليم من ناحية الإشراف والدعم

\section{الفني.}

\section{مكافحة الأميَّة وتعليم الكبار}

تقتم الدولة بمكافحة الأمية وتعليم الكبار، وتدعم هذا النوع من التعليم فنيَّا وماليا وإداريا، وذلك تحقيقا لرفع مستوى الأمة، وتعميم الثقافة بين أفرادها.

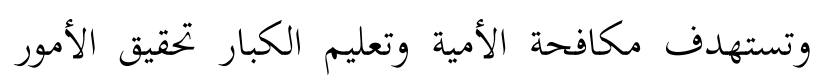
الأساسية التالية: - n ( ) تنمية حب الله وتقواه في قلوبهم وتزويدهم بالقدر

$$
\begin{aligned}
& \text { الضروري من العلوم الدينية. } \\
& \text { r) تعليم القراءة والكتابة ومبادئ الحساب. } \\
& \text { r) التوعية العامة في شؤون الحياة. }
\end{aligned}
$$

ع) توضع من قبل الجهات التعليمية المختصة خطة زمنية قائمة على الإحصاء لاستيعاب الأميين، والقضاء على الأمية، وتتعاون في تنفيذها الوزارات
وتوضع لغير المؤهلين مسلكيّا خطة لتدريبهم وتأهيلهم، كما توضع خطة للمؤهلين لرفع مستواهم وبتحيد

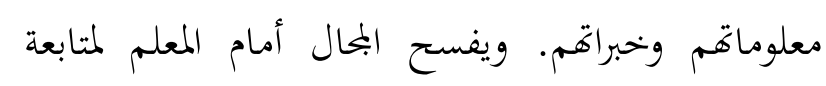

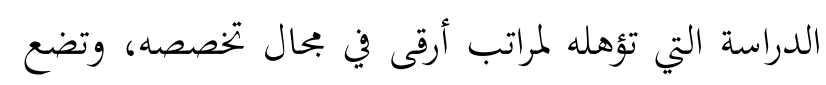

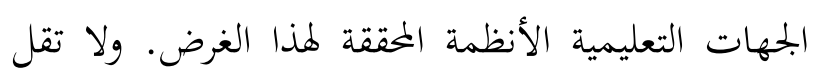
مدة إعداد معلمي المرحلة الابتدائية عن المدة اللازمة

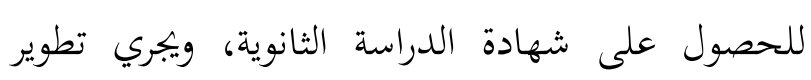
مرحلة إعداد المعلمات تدريجيا لتحقيق ذلك، ولا تقل مدة إعداد معلمي المرحلتين المتوسطة والثانوية عن المدة اللازمة للحصول على شهادة التعليم العالي.

\section{التوسع في نشر مدارس القر آن الكريم ومعاهده} تعمل الدولة علي إشاعة حفظ القرآن الكريم، ودراسة علومه، قياما بالواجب الإ سلامي في الحفاظ على إلى لئه الوحي، وصيانة تراثه. يفتح لهذا الغرض نوعان من المدارس: وصياله نراهئ أ- مدارس مسائية: للراغبين في حفظ القرآن من من من لفرعن السعوديين وغيرهم، وتخصص لهم لموائز تشجيعية وفق لائحة تنظم ذلك.

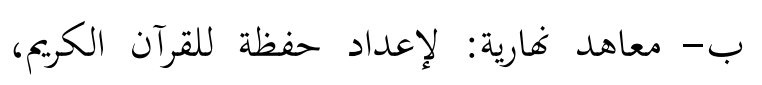
ومدرسين له وللعلوم الدينية، وإعداد أئمة

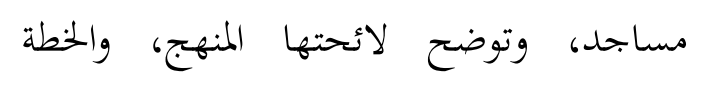
التفصيلية، والسنوات الدراسية والطاقات والجوائز

$$
\text { والمميزات التشجيعية. }
$$

\section{التعليم الأهلي وتنظيم عمله}

تشجع الدولة التعليم الأهلي في كافة مراحله، ويخضع لإشراف الجهات التعليمية المختصة فنيًّا وإداريًّا. ويوضح ذلك النظام الخاص به. والترخيص بافتتاح 
والمصالح المعنية. تكون فترة المكافحة والتعليم على مواهبهم وتوجيهها، وإتاحة الفرصة أمامهم في بحال

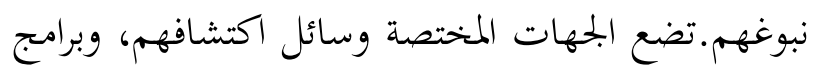

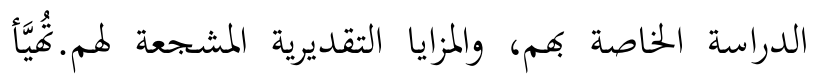

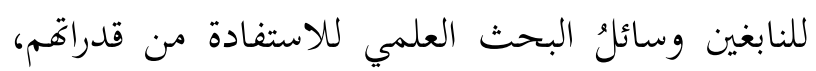
مع تعهدهم بالتوجيه الإسلامي.

الاعتناء بالمناهج الدراسية باعتبارها وسيلة تربوية عامة تعنى الدولة بالمناهج الدراسية باعتبارها وسيلة هامة من وسائل التربية والتعليم. ينبغي ان تكون هذه المناهج:

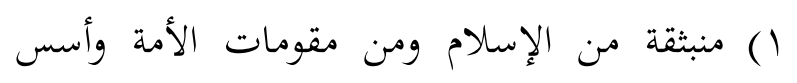
نظامها.

Y Y موافقة لحاجات الأمة، وترمي إلى تحقيق أهدافها. r ب (r) مناسبة لمستوى الطلاب. ع) محقة للمستوى المطلوب في الدارسين ولأهداف مستول التعليم. 0) متوازنة، ومرنة، وتوافق مختلف البيئات والأحوال. وتتضمن المناهج: •الهدف العام وارتباطه بهدف الدولة من التربية العناية بالفروقات بين الطلاب في الصحة والنبوغ العناية بالفروقات بين الطلاب في الصحة والنبوغ والتعليم. الأهداف الخاصة بكل من المرحلة التعليمية والمادة العلمية. تحديد المستويات العلمية والمهارات العملية

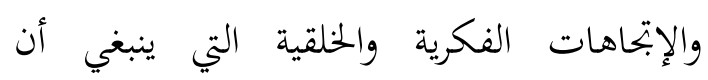
تحققها. التوجيهات التي تقود خطوات المعلم في تحقيق الأهداف وتطبيق المنهج. النشاط المدرسي المرافق للدروس والمحقق لأغراض هدف كل وحدة من وحدات المنهج. المرحلة الأولى: وتنتهي بالحصول على شهادة محو الأمية. المرحلة الثانية: المتابعة لنيل الشهادة الابتدائية.

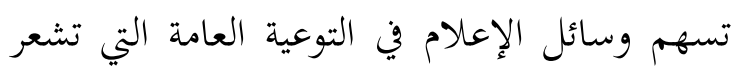

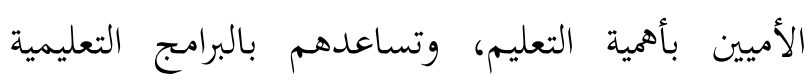

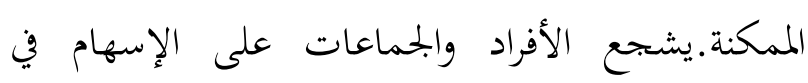
مكافحة الأمية وتعليم الكبار تحت إشراف الجهات

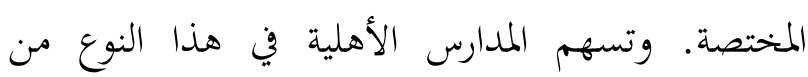
التعليم، ولاتصرف إعاناما إلا إذا شاركت بنصيبها المقرر

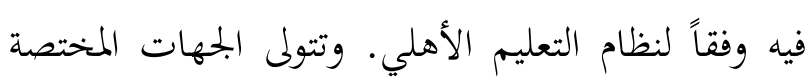

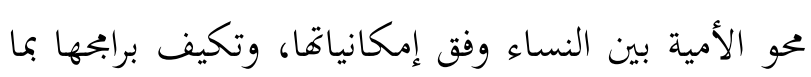
يحقق الأهداف الخاصة بتعليم المرأة وفقاً لأحكام الإسلام. تُعنى الدولة وفق إمكانياها بتعليم المعوقين ذهنيا أو جسميَّا، وتوضع مناهج خاصة ثقافية وتدريبية متنوعة

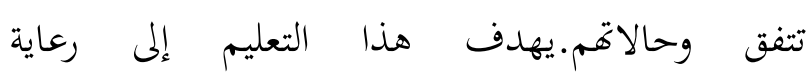
المعوقين،وتزويدهم بالثقافة الإسلامية والثقافة العامة اللازمة لهم، وتدريبهم على المهارات اللائقة بالوسائل

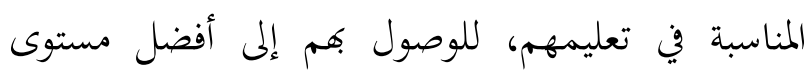

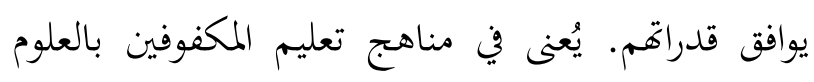
الدينية وعلوم اللغة العربية.

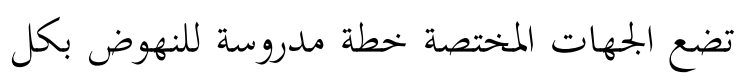

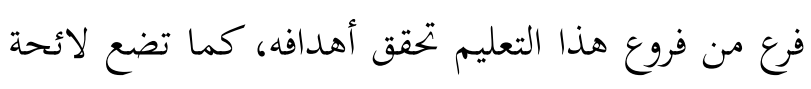
تنظم سيره.ترعى الدولة النابغين رعاية خحاصة لتنمية 


\section{نشر المكتبات والتشجيع على التأليف}

تعنى الدولة بإنشاء المكتبات العامة، وتوفر في هذه

المكتبات المراجع والمصادر والكتب التعليمية والتثقيفية

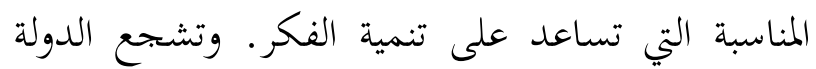

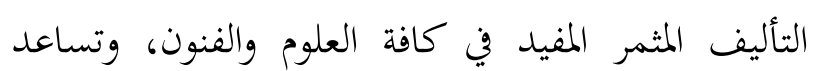
كتابها الإسلاميين على نشر الكتاب الجيد وتعميم

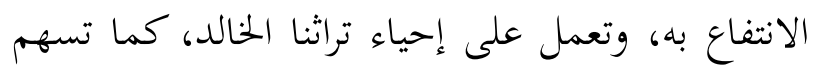
بنصيب وافر في مشروعات النشر المحقة لذلك.وتتم

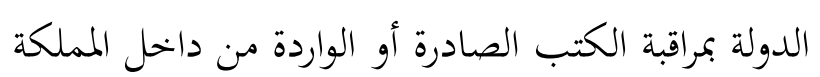

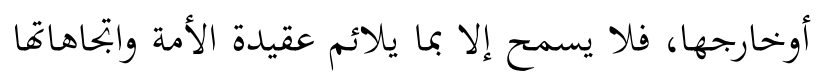

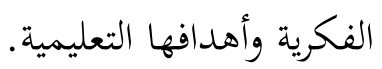

تكون الصحف والمحلاتمنسجمة مع أهداف التعليم في التوجيه والتربية، والفكرة والغاية.تعمل الجهات

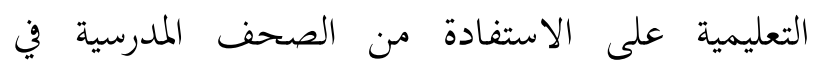
التوجيه، وتقوم بإصدار بحلة خاصة تعبر تعبيراً صادقاً عن التعنية المنهج القويم الذي ارتضته المملكة لتعليم أبنائها، وروح

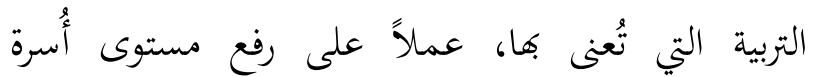
التعليم.توصدر الجهات التعليمية المختصةالنشرات التثقيفية والتوجيهية والإدارية حتى يساعد ذلك الجهاز الإداري والجهاز الفني على تطبيق السياسة التعليمية.

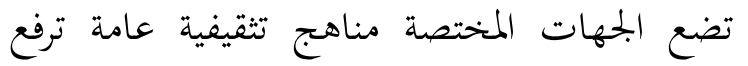
المستوى الإسلامي للفرد والمحتمع من النواحي الفكرية

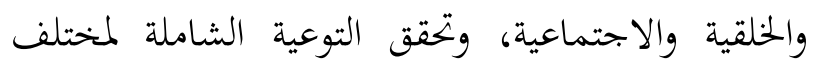
الشؤون في كافة المستويات.وسائل الإعلام والنشر والتوعية والإرشاد ورعاية الشباب تخدم الفكرة الإسلامية

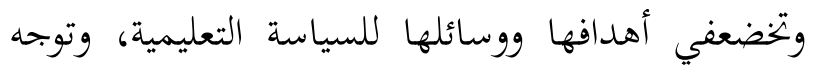

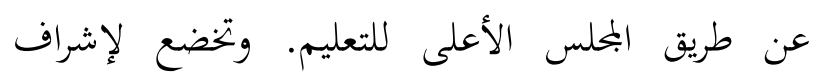

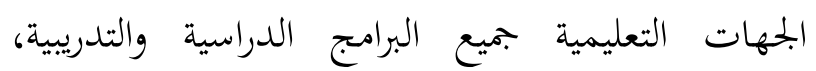

قياس تقدم الطلاب فيه.

يكون الكتاب المدرسي منسجما مع مقتضيات الإسلام، سليم اللغة، وافيا بأهداف المنهج ومقاصده العلمية والعملية والخلقية.

يوضح نظام التخطيط للكتاب المدرسي "أوصاف وافلية. الكتاب" والإجراءات المناسبة ليكون على أفضل الوجوه.

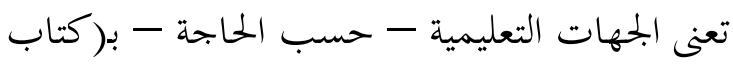
المعلم) الذي يساعد على توضيح سياسة الدولة في التربية والتعليم، ويعين معلم كل مادة على تحقيق أهداف المنهج من النواحي التعليمية والتربوية، كما يكون دليلا مساعدا في حسن استخدام الكتاب المدرسي.

\section{العناية بالاختبارات لما لها من أهمية}

تجري الجهات التعليمية الامتحانات للكشف في دقة ونزاهة عما بلغه الطلاب من المستوى الذي حدده المنهج في المعلومات والخبرات والمهارات، ويوضح النظام

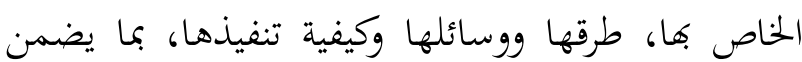
سلامتها وحسن سيرها ودقة نتائجها. تعنى الجهات المختصة بالاختبارات الأخرى التي

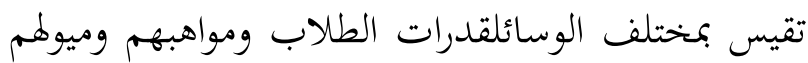
واستعداداقمى، توطئة لحسن توجيهمم إلى مايصلحون له

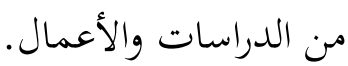
تقوّم العملية التعليمية في مختلف جوانبها من المنهج والمعلم والكتاب وطرائق التدريس وأساليب "التوجيه

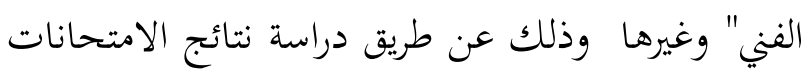
واستخدام سائر وسائل التقويم. 
توفر الدولة فروع التعليم العالي على اختلاف أنواعها

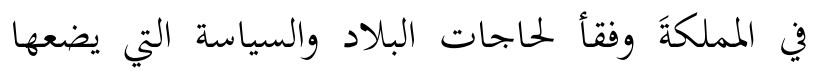
البحلس الأعلى للتعليم.

\section{المبادرات والمشاريع للتربية في المملكة} هناك مبادرات ومشاريع رئيسية يمكن سردها على النحو

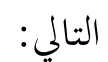

أولاً: مشروع الملك عبدالله بن عبدالعزيز لنطوير التعليم العام

$$
\text { ( ) تم إعادة هيكلة المشروع. }
$$

Y) تم إعداد خطة استراتيجية لتطوير التعليم العام

$$
\text { وبرؤية موححة. }
$$

r بتم تنفيذ الخطة الاستراتيجية من خلال شركة تطوير للخدمات التعليمية (شركة مملوكة بالكامل

$$
\text { للدولة) وبتكامل مع الوزارة. }
$$

ع) ت تم تأسيس شركة تطوير للخدمات التعليمية.

$$
\text { بعض برامج الخطة الاستراتيجية ومشاريعها: }
$$

( ) برنامج تطوير المدارس وإدارات التربية والتعليم.

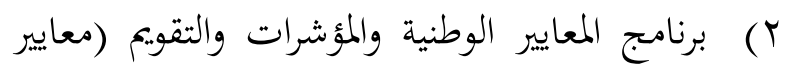
التعلم، معايير العاملين في التعليم، معايير البيئة

$$
\text { المدرسية). }
$$

r

$$
\text { التعليم. }
$$

ع) برنامج تطوير التعليم الثانوي.

ه) برنامج تطوير التربية الإسلامية.

7) برنامج تطوير تعليم اللغة العربية.

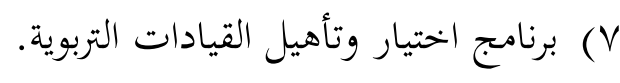

^) برنامج تطوير تعليم اللغة الإنحليزية.
والنوادي والمراكز الثقافية والمعاهد التي تقيمها الوزارات أو

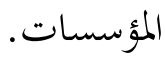

\section{التوسع في أفاق المعرفة والنشر لها}

تعمل الدولة على نشر الثقافة الإسلامية بكافة

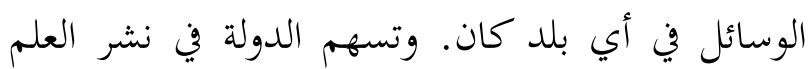
والمعرفة بين الدول والأمم والشعوب بالأمور الآتية: ( ) إيجاد منح دراسية يحددها البحلس الأعلى للتعليم

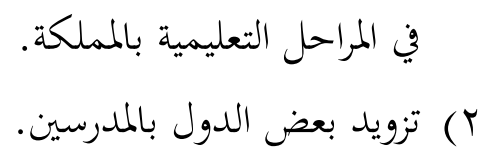

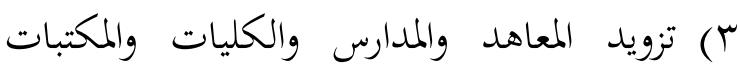
العامة بالكتب والصحف والنشرات المفيدة.

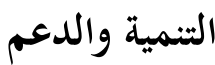

تعتبر الدولة أن الطاقة البشرية هي المنطلق في

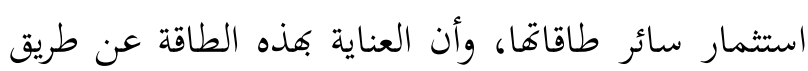
التربية والتعليم والتثقيف هي أساس التنمية العامة. وتراعي لـائي الدولة زيادة نسبة ميزانية التعليم لتواجه حاجة البلاد التعليمية المتزايدة، وتنمو هذه النسبة مع نمو الميزانية العامة. ولدرجات الطلاب في الجد والاستقامة.

\section{المخدمات الجلانية من الدولة}

التعليم بحاني في كافة أنواعه ومراحله فلا تتقاضى

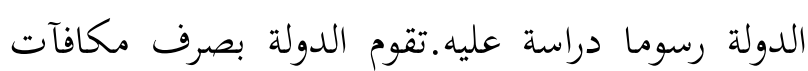
وقتية للطلاب في أنواع معينة من التعليم والتدريب. ويكون تقدير هذه المكافآت وتحديد جهاتها وإعادة النظر فيها بين حين وآخر من اختصاص البملس الأعلى للتعليم

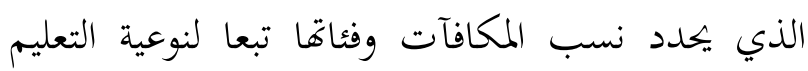
ولدرجات الطلاب في الجحد والاستقامة. 
(V البدء بقياس الأداء من خلال نظام للأداء والتميز.

ثالثًا: مبادرة تقويم التعليم العام.

هيئة تقويم التعليم العام، أقر بحلس الوزراء الموقر

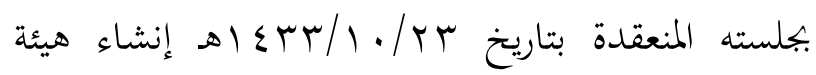
عامة لتقويم التعليم العام، تتمتع بالاستقلال الإداري والمالي، ويكون مقرها الرياض، ولها محافظ بالمرتبة الممتازة، وترتبط الهيئة تنظيميًا برئيس بحلس الوزراء مؤقتًا، وبرئيس البحلس الأعلى للتعليم عند إنشائها.

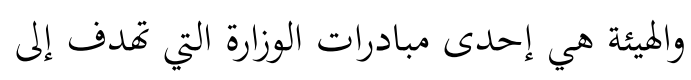

الوقوف على أداء المؤسسات التعليمية، وتعمل على تحسين الأداء العام من خلال دراسة نقاط الضعف والقوة واقتراح فرص التحسين. والاستقلالية تعد أهم الملامح المستهدفة للهيئة.

وستمارس الهيئة عددًا من المهام أبرزها:

( ) تأسيس نظام للتقويم ومراقبة تطبيق معايير الجودة

$$
\text { في التعليم العام. }
$$

r) بناء معايير متقدمة لمراحل التعليم تستخدم لقياس كفاءة الأداء في المدارس الحكومية والأهلية،

$$
\text { واعتمادها بشكل دوري وفق معايير الهيئة. }
$$

r) بناء معايير مناهج التعليم وتحديد ما يجب أن يعرفه

$$
\text { الطالب في كل مرحلة. }
$$

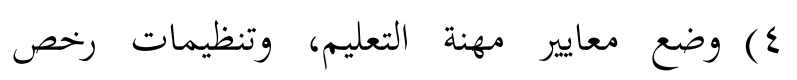

$$
\text { المعلمين. }
$$

$$
\text { 0) إجراء الاختبارات الوطنية. }
$$

رابعًا: مبادرة تعزيز مشاركة القطاع الخاص في التعليم

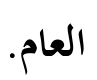

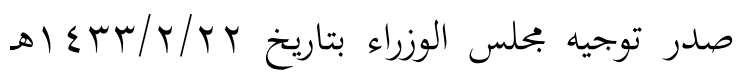
بتعزيز مشاركة القطاع الخاص في التعليم العام للإسهام في
9) برنامج تطوير تعليم العلوم والتقنية والهندسة والرياضيات (التدريب، المراكز العلمية، المسابقات، لركونج

$$
\text { وغيرها). }
$$

• (1) تطوير التعليم في مرحلة الطفولة المبكرة. (1) (1) تطوير برامج التربية الخاصة.

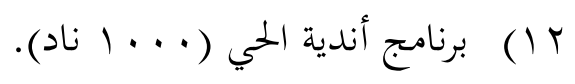

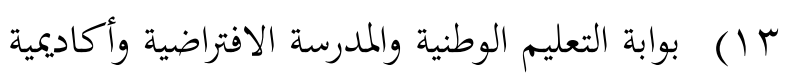

$$
\text { التطوير المهني الافتراضية. } 17
$$

ع () برنامج تطوير الرياضة المدرسية. 1 ) برنامج التطوير المهني للمعلم الجديد.

\section{ثانيًا: مبادرة التوحيد واللامركزية:}

توحيد الإجراءات بين القطاعات يمثل استراتيجية

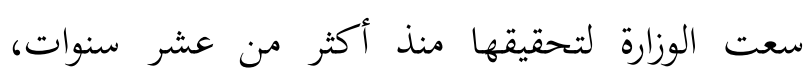
ونشير هنا إلى ما تحقق في هذه الاستراتيجية خلال السنوات الماضية فيما يلي: ( ) السعي إلى التركيز في عمل جهاز الوزارة على وضع لئي السياسات والخطط والإشراف العام. ץ) تم توحيد عدد من الوكالات والإدارات المتناظرة

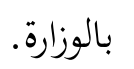

r

$$
\text { (0) إدارة، وكانت قبل ذلك بر إدارة). }
$$

ع) تم تعزيز اللامركزية في المناطق والمحافظات والمدارس

$$
\begin{aligned}
& \text { من خلال التوسع في صلاحيات مديري التربية } \\
& \text { والتعليم، وصلاحيات مديري المدارس. } \\
& \text { 0) تم منح ميزانيات تشغيلية للمدارس. }
\end{aligned}
$$

ج) تم تشجيع التنافس بين إدارات التربية والتعليم وبين

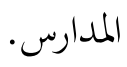

$$
7 \text { أحمد الرومي - عامر السويداني، لمحات من المسيرة. }
$$




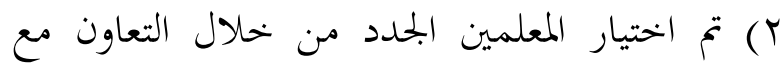
المركز الوطني للقياس، وسيطبق على المعلمات قرييًا.

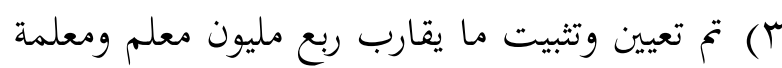

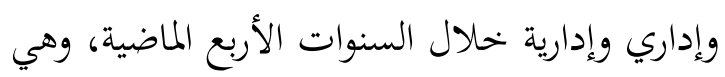

$$
\text { إبحازات غير مسبوقة من حيث الحكم. }
$$

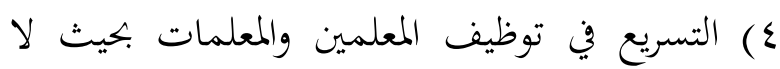
يكون هناك إرباك في بداية العام.

0) تنفيذ مشروع المعلم الجديد لتدريبهم وقيئهم

$$
\text { المعلمون في المدارس. }
$$

1) تم نقل جميع المعلمات المتقدمات بطلب النقل على رلى المعلى

$$
\text { رغبتهن الأولى. }
$$

T (Y) معالجة وضع الحاصلين على شهادة الماجستير

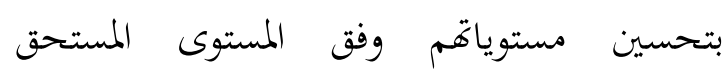

$$
\text { (السادس). }
$$

r معالحة التباين الحاصل في رواتب المعلمين والمعلمات المعينين بصفة رسمية على المستويات التعليمية في عام واحد ووفق مؤهل دراسي واحد. ع) معالجة نقص رواتب المعلمين والمعلمات التربويين عن غير التربويين. 0) معالجة أوضاع الدفعات الأخيرة من خريجي كليات المعلمين.

7) معالجة وضع خرييجي دبلوم التربية الخاصة بعد الجامعي بمنحهم المستويات المستحقة.

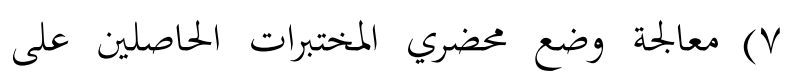
الشهادة الجامعية وهم على رأس العمل. ^) رفع المؤهلات العلمية للمعلمين. 9) الرفع بلائحة جديدة للوظائف التعليمية تشمل

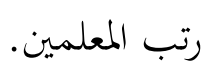

رفع جودة التعليم العام، ورفع كفاءته، مع المحافظة على بحانية التعليم، وذلك بناءً على الخطاب المرفوع للمقام

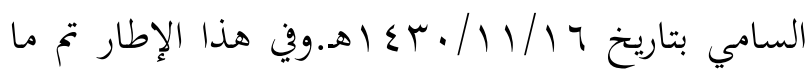
يلي: - n - n () إعداد استراتيجية لتعزيز مشاركة القطاع الخاص في التعليم العام. r تأسيس شركة تطوير التعليم القابضة (مملوكة بالكامل للدولة). r) تأسيس (ץ) شركات حكومية تابعة لشركة تطوير

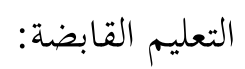
أ- شركة تطوير للخدمات التعليمية (المناهج) التدريب، المعاير، النشاط اللاصفي، وغيره). ب- شركة تطوير للنقل المدرسي. ت- شركة تطوير للمباني المدرسية. ث- سيتم بإذن الله تأسيس شركات أخرى تخدم الوزارة في مراحل مختلفة وفق دراسات الجحدوى. ج-صدرت موافقة الجهات العليا لإسناد التغذية دراسية

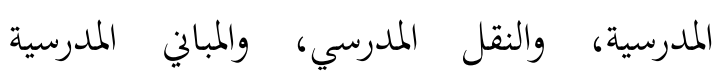
للشركات أعلاه، بحيث تتفرغ الوزارة وإدارات التربية والتعليم لمهامها الرئيسية. خامسًا: مبادرات موجهة للمعلمين والمعلمات ومن في

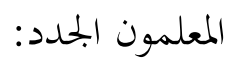

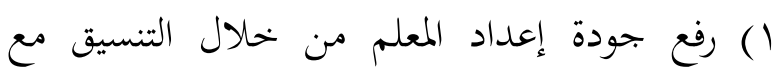
الجحامعات السعودية حول الخطط الدراسية ومعايير

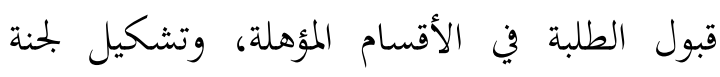
دائمة للتنسيق مع وزارة التعليم العالي. 
^) يتم حاليًا تطوير مناهج المرحلة الثانوية للمواد الدينية واللغة العربية والاجتماعية. 9) يتم حاليًا تطوير مناهج الحاسب الآلي.

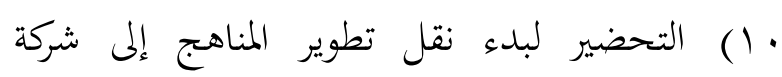
تطوير للخدمات التعليمية، مع إبقاء الأدوار الضرورية في الوزارة.

\section{سابعًا: مبادرة التوسع في رياض الأطفال}

(1) أثبتت الدراسات أن رياض الأطفال مهمة جلدً لتكوين شخصية الطفل وتعزيز بحاحه في المستقبل.

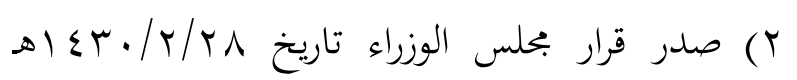
بالتأكيد على الإسراع في جعل رياض الأطفال

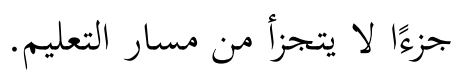

r) يتم تنفيذ مبادرة للتوسع في رياض الأطفال لاستيعاب . ه\% من الأطفال من خلال: ع) توسيع الشراكة مع القطاع الخاص. 0) اقتراح آلية مطورة للإقراض الميسر للمستثمرين. 7) تسهيل إجراءات إنشاء رياض الأطفال الأهلية. V رفع وعي الأسرة بأهمية رياض الأطفال. م) دعم الوزارة بسبعة آلاف معلمة لرياض الأطفال. 9) تم افتتاح ما يقارب ... بم روضة أطفال العام الماضي (بمعدل روضة أطفال واحدة يوميًا)، وافتتاح أكثر من . V. روضة أطفال هذا العام (بمعدل

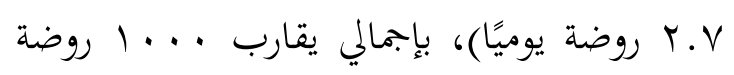

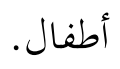

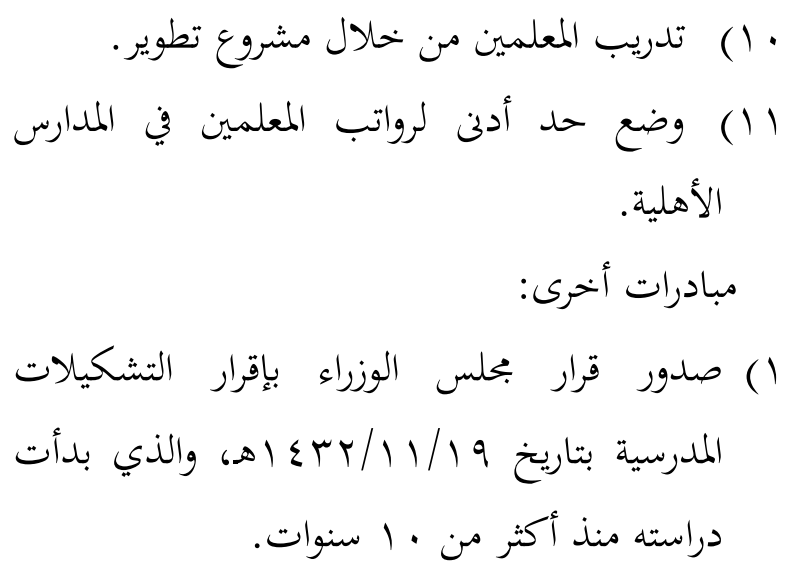

Y) إطلاق جائزة سنوية للتميز تستهدف تكريم المعلمين ومديري المدارس والمرشدين والمشرفين التربويين.

r والمعلمات. ع) تم تشكيل بحلس استشاري للمعلمين في كل إدارة تعليمية لإشراكهم في اتخاذ القرارات. سادسًا: مبادرات المناهج. () تم تطبيق المناهج الجديدة للرياضيات والعلوم في جميع المراحل والمدارس. Y (Y) تطبيق مناهج المشروع الشامل للمناهج للمرحلتين الابتدائية والمتوسطة في جميع المدارس.

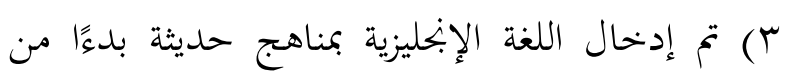
الصف الرابع، وسيتم تغطية جميع الصفوف وجميع المدارس قريبًا. ع) تم التوسع في تطبيق نظام المقررات في التعليم الثانوي. ه) تم تدريب أعداد كبيرة من المعلمين والمشرفين على الم المناهج الجديدة. ج) يتم حاليًا تطوير مناهج التربية الخاصة. V يتم حاليًا تطوير مناهج لرياض الأطفال. 
إجمالي طالبات التعليم العام).صدرت موافقة بحلس الوزراء

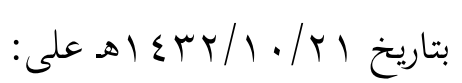

(1) مضاعفة أعداد الطالبات المستفيدات (أكثر من المبن

$$
\text { مليون ومئتي ألف طالبة). }
$$

r T البدء بتقديم الخدمة للطلاب والمعلمات.

r) تم إعداد خطة للتوسع في مشروع النقل المدرسي

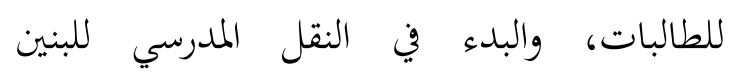
والمعلمات.

ع) البدء بنقل خدمات تقديم النقل المدرسي إلى شركة

$$
\text { تطوير للنقل التعليمي. }
$$

عاشرا: مركز للخدمات المساندة للتربية الحخاصة:

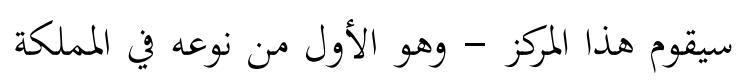
- بتقديم خدمات مساندة للمساعدة في تأهيل الأطفال ذوي الإعاقات الخاصة القابلة للعلاج، وكذلك للأطفال

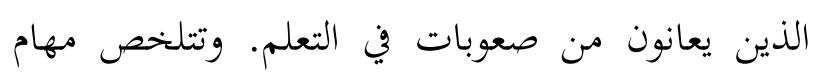

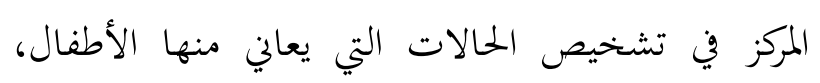

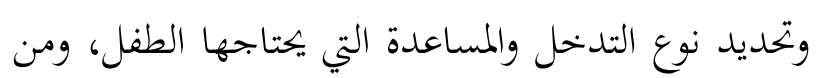
ثم إحالته إلى جهة الاختصاص في المركز، التي تقوم بدورها

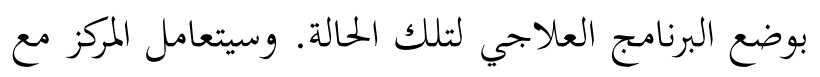

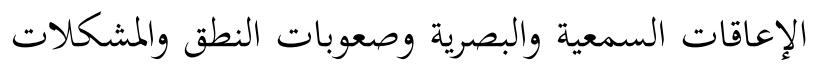
السلوكية وحالات التوحد وصعوبات التعلم. وتم إسناد

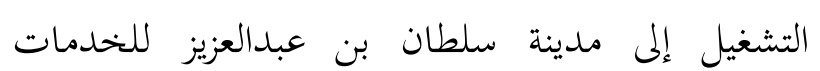
الإنسانية. هذا ولا زال في جعبة وزارات التربية والمؤسسات

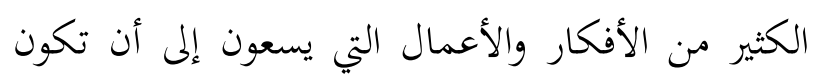

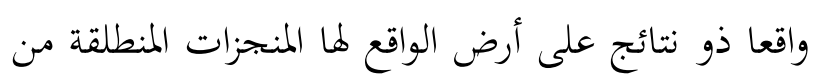

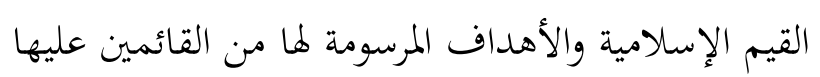

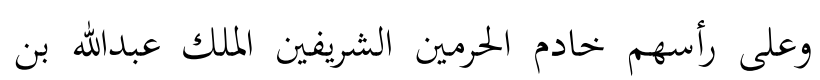

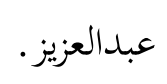

1) استلام . .r.r مشروع خلال السنوات الأربع

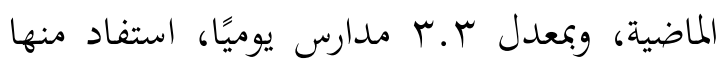

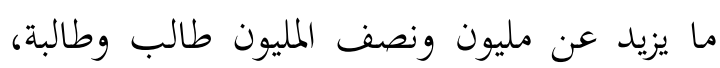
وذلك يعادل • ؟٪\% من إجمالي الطلاب والطالبات.

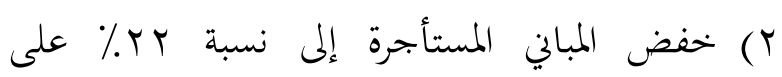

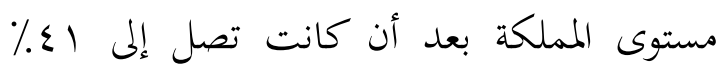

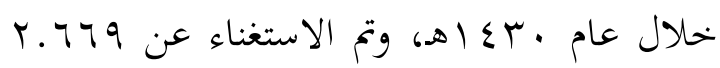

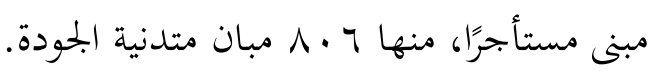

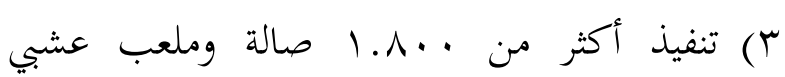
خلال السنوات الأربعة الماضية.

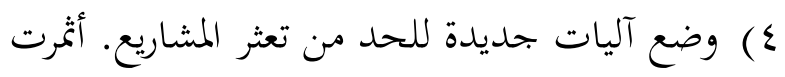

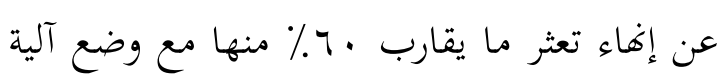
موحدة لضبط جودة المشاريع.

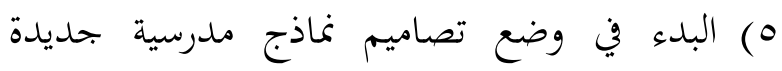
بمشاركة استشاري عالمي. 4) البدء في استخدام أنظمة بناء جديدة وسريعة البتارئ لتغطية الاحتياج العاجل من المباديان النطمة بناء جلمديده وسريعة المدرسية

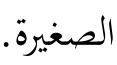

V لمنح المزيد من الصلاحيات لإدارات التربية والتعليم للحد من المركزية بأساليب تكفل سرعة الإنحاز

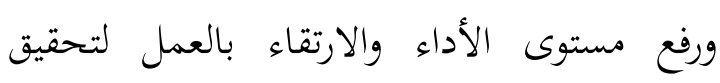
استراتيجيات وتوجهات الوزارة.

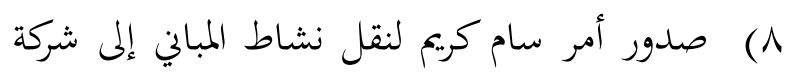
تطوير للمباني، والبدء في التحضير لذلك.

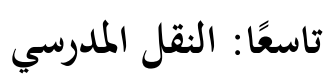
إسناد تشغيل النقل المدرسي للطالبات في جميع

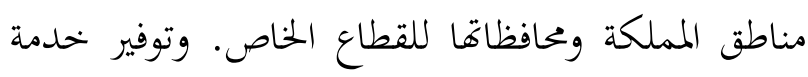

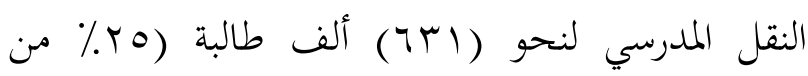


التعليم, -الأسس -الأهداف-وبعض وسائل

الحاتمة

تحقيقها -الاتجاهات -نماذج من المنجزات،

.p) 9976 b

رومي، أحمد - عامر السويداني، لمحات من المسيرة،

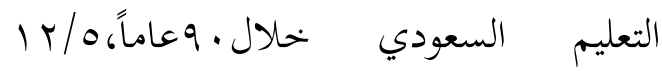

$\rightarrow \leqslant r \leqslant \mid$

رومي، أحمد، عامر السويداني، لمحات من المسيرة التعليم

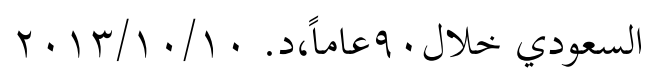

زهراني، سعود حسين،المعلم سعودي، إعلداده وتلديبه

وتقويمه: سعود حسين الزهراني، دار البلاد

للطباعة والنشر، جدة، ط: ال، 1 إع اهـ.

زيد، عبد الله محمد ، التعليم في المملكة العربية السعودية

أنموذج نختلف، ، طـ؛ جدة: الدار السعودية

$$
\text { للنشر والتوزيع 11 1ـ اهـ-. } 199 .
$$

سنبل، عبدالعزيز بن عبد الله وآخرون، نظام التعليم في

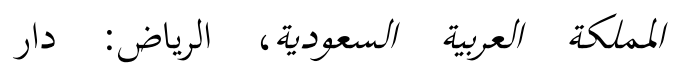

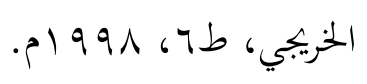

ظهار، بجاح بنت أحمد ،تعليم المرأة في المملكة العربية السعودية وازدهاره في عهد الملك فهد (بمناسبة

مرور عشرين عاماً على بيعة خادم الحرمين

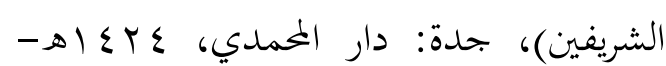

$$
\text { . Pr. r }
$$

عساف، صالح ، المدنحل إلى البحث في العلوم السلوكية،

$$
\text { ط 1، الرياض: دار الزهراء، · ل • ب م. }
$$

علي، سعيد إسماعيل، و وآخرون، التربية الإسلامية،

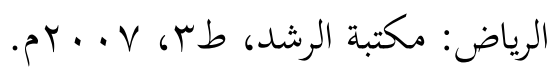

استعرضنا سبع مباحث تهكي باختصار نظام

وأسس التربية الإسلامية في المملكة ونوصي كل الدول

الإسلامية أن تنطلق من هذا الدين وسماحته وشموله وعالميته لتكون كل أنظمتها تتماشى معه وأولها نظام التربية الذي هو يعتبر الخط الأول لمعترك الحياة وتأسيس النواة الفردية والأسرية والمجتمعية؛ فإن كان نظام تربويا إسلاميا بشقيه العلمي المعريف والتطبيقي فازت بعدة خصال ومنها طاعة الله سبحانه وتعالى وامتثال أوامره والفوز بجنته ثم سلمت من التناقضات والتبعية والتخبط

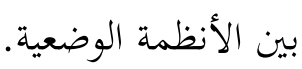

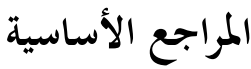

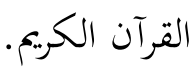

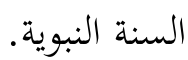

أحمد، رشيد محمد، التعليم العالي وسوق العمل، ندوة التعليم العالي في المملكة العربية السعودية رؤى

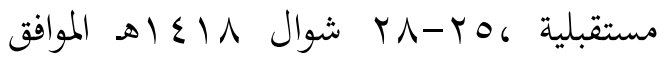

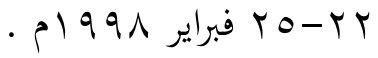

أحمد، رشيد محمد، سياسة التعليم في المملكة العربية السعودية، وزارة التعليم العالي/ ووزارة التربية والتعليمرؤية مستقبلية للتربية والتعليم في المملكة

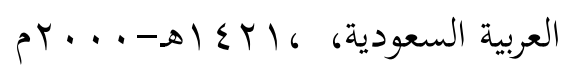

حازمي، خالد بن حامد، أصول التربية الإسلامية، طا القاهرة: عالم الكتب، . . . ب م.

حقيل، سليمان بن عبد الرحمن ، نظام ومياسة التعليم في المملكة العربية السعودية الجنور التاريخية لنظام 


\section{8 | TARBIYA | Vol. I, No.1, Juni 2014}

نحلاوي، عبد الرحمن، أصول التربية الإسلامية وأماليبها

مسعود، عبدابلجيد، نحو نظرية تربوية إسلامية: ملامح في البيت والملارسة والمجتمع ، دمشق: دار أولية، المملكة العربية المغربية، دراسات عربية في

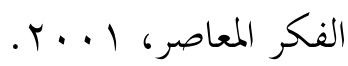
التربية وعلم النفس، العدد الرابع والثلاثون،

نحلاوي، عبدالرحمن، أسس التربية في التربية الإسلامية

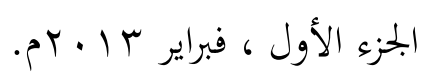

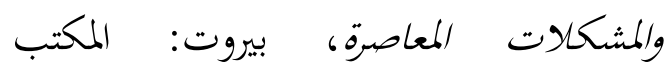

ميمان، صالح بدرية ، "أسس التربية الإسلامية بين التنظير الإسلامي، والتطبيق، في سياسة التربية والتعليم في المملكة

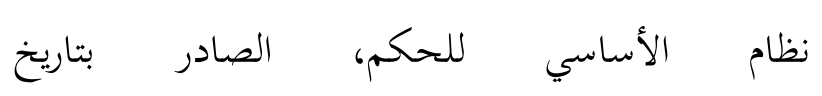
العربية السعودية"، بحث متحم للقاء السنوي

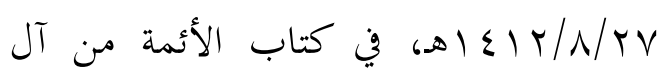
الحادي عشر للجمعية السعودية للعلوم التربوية سعود والنهج الإسلامي الفريد: فهد عبدالعزيز الكليب ط: المركز الوطني للدراسات والنغسية (جستن) المنعقد في جامعة المللك سعود بالرياض في الفترة • بإبريل-1 مايو،

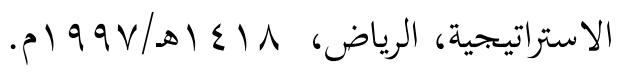

